\title{
35. CHANGES IN KEROGEN COMPOSITION ACROSS AN OXIDATION FRONT IN MADEIRA ABYSSAL PLAIN TURBIDITES AS REVEALED BY PYROLYSIS GC-MS ${ }^{1}$
}

\author{
Marcel J.L. Hoefs, ${ }^{2}$ Jaap S. Sinninghe Damsté, ${ }^{2,3}$ Gert J. De Lange, ${ }^{2}$ and Jan W. de Leeuw ${ }^{2,3}$
}

\begin{abstract}
Isolated kerogens from Madeira Abyssal Plain turbidite samples were qualitatively and semiquantitatively studied by means of analytical pyrolysis for the effect of oxygen exposure on organic matter preservation. The initial organic matter in the turbidite is very homogeneous and relatively high and offers an ideal case for the study of oxygen effects on organic matter preservation without the usual complications of varying sources or sedimentation rates and bioturbation. From all four studied turbidites, one sample from the oxidized part of the turbidite was compared with two samples from the unoxidized part. The aliphatic character of the kerogens after postdepositional oxidation has increased significantly, as revealed by the abundance of the $n$-alkanes and $n$-alk-1-enes in the oxidized turbidite. At the same time, the contribution of the isoprenoid alkanes and alkenes and the alkylthiophenes to the pyrolysate has decreased significantly. The relative abundances of alkylbenzenes, alkylnaphthalenes, alkylphenols, alkylindenes, and alkan-2-ones in the pyrolysates have remained relatively constant upon oxidation. The alkylbenzene, alkylphenol, alkylnaphthalene, $n$-alkane, and $n$-alk-1-ene, isoprenoid alkane, and alkene internal distributions are substantially altered in the oxidized samples. This study shows that postdepositional oxidation of sedimentary organic matter by oxygen is far more severe than by sulfate alone. Furthermore, it is clear that oxidation of the organic matter is, to a significant degree, selective.
\end{abstract}

\section{INTRODUCTION}

The influence of oxygen on organic matter preservation has been an intensely debated issue for a long time. Generally, there are two schools of thought. One argues that the presence or absence of $\mathrm{O}_{2}$ has little or no effect on organic matter preservation (e.g., Henrichs and Reeburgh, 1987; Pedersen and Calvert, 1990; Calvert and Pedersen, 1992; Calvert et al., 1992), whereas the other school states the opposite (e.g., Demaison and Moore, 1980; Pratt, 1984; Canfield, 1989, 1993; Paropkari et al., 1992).

The Madeira Abyssal Plain (MAP) region is a unique site for the study of the effect of oxygen on organic matter preservation. The distal, organic matter-rich turbidites, derived from the northwest African margin, are almost perfectly mixed and laid down as a homogeneous deposit (De Lange et al., 1987; Morris, 1987; Prahl et al., 1989). All of these turbidites contain a sharp oxidation front down to which bottom-water oxygen has penetrated the sediment. This postdepositional oxidation process was terminated by the deposition of the next turbiditic sequence. The penetration of oxygen resulted in the destruction of as much as $80 \%$ of the organic matter $(\mathrm{OM})$ in the oxidized layer, whereas the unoxidized part of the same turbidite has remained unaffected despite prolonged exposure to pore-water sulfate (e.g., 140 k.y. for the MAP f-turbidite [De Lange et al., 1987; see Weaver and Kuijpers, 1983, for turbidite letter designations]). These organic matter-rich MAP turbidites form an ideal site to study the effect of oxygen on organic matter preservation because of their homogeneity; this ensures that the organic matter that is exposed to the oxidation process by molecular oxygen was initially the same throughout the turbidite. Thus, compositional differences that occur after the oxidation process is terminated can be related only to the effect of molecular oxygen on organic matter preservation and not to the host of other variables that normally affect the composition of organic

${ }^{1}$ Weaver, P.P.E., Schmincke, H.-U., Firth, J.V., and Duffield, W. (Eds.), 1998. Proc. ODP Sci. Results, 157: College Station, TX (Ocean Drilling Program).

${ }^{2}$ Utrecht University, Institute of Earth Sciences, Department of Geochemistry, P.O. Box 80.021, 3508 TA, Utrecht, The Netherlands.

${ }^{3}$ Netherlands Institute for Sea Research (NIOZ), Division of Marine Biogeochemistry and Toxicology, P.O. Box 59, 1790 AB, Den Burg, Texel, The Netherlands (Corresponding author: Damste@nioz.nl). matter in marine sediments (e.g., varying productivity, sediment accumulation rate, OM source, reworking, bioturbation, seasons).

In the past, several organic geochemical studies of MAP turbidites have been performed. Morris (1987) reported that phytoplanktonic debris was a major component of the original OM in the MAP h-turbidite. Although the turbidite is of considerable age (190-247 k.y.), unsaturated fatty acids and sterols were still important components of the extractable lipids, even in the oxidized part of the turbidite. Morris (1987) concluded that anaerobic reduction of oxidants other than oxygen was the primary mechanism responsible for the degradation of the OM. Cowie et al. (1995) studied the $\sim 140-k . y .-o l d$ f-turbidite and found that $80 \%$ of the initial OM and $60 \%$ of the initial total nitrogen were removed from the oxidized samples. They also found a decrease of the atomic $\mathrm{C}: \mathrm{N}$ ratio from $\sim 11$ to 5 . The predominantly marine $\mathrm{OM}$ yielded low amounts of lignin phenols, in both oxidized and unoxidized samples, and comparable total organic carbon (TOC) normalized neutral sugars and total hydrolyzable amino acids. It was concluded that the OM was degraded largely nonselectively upon oxic degradation, although oxic degradation was far more extensive than degradation with sulfate alone. Prahl et al. (1997), on the other hand, concluded that TOC degradation is to some extent compound selective, because some marine phytoplankton biomarkers and plantwax $n$-fatty acids were lost from the oxidized samples to an extent at least as great as that for TOC, and higher plantwax-derived $n$-alkanes were enriched relative to TOC. They also reported that the OM was composed of marine and terrestrial components. The terrestrial component was proposed to be preferentially preserved in the oxidized samples, composing $\sim 15 \%$ of TOC in the unoxidized sample to $\sim 30 \%-60 \%$ of TOC in the oxidized samples. The decrease of $\sim 1.7 \%$ o to $2.9 \%$ in $\delta^{13} \mathrm{C}_{\mathrm{TOC}}$ of the oxidized samples, was in line with this assumed larger contribution of terrestrial OM in the oxidized turbidite. For MAP turbidite a, which is presently being oxidized, McArthur et al. (1992) reported a 35\% decrease in TOC and a decrease of $\leq 0.3 \%$ in $\delta^{13} \mathrm{C}_{\mathrm{TOC}}$. Turbidite e, where postdepositional oxidation has ceased, showed a $50 \%$ decrease in TOC without any change in $\delta^{13} \mathrm{C}_{\mathrm{TOC}}$, but further oxidation of the more refractory $\mathrm{OM}$ by an additional $25 \%$ resulted in a decrease in $\delta^{13} \mathrm{C}_{\mathrm{TOC}}$ by $2.5 \%$.

The long-chain alkenones, derived from, for example, the prymnesiophyte alga Emiliania huxleyi, were degraded in the MAP f-turbidite by $>85 \%$ as a consequence of diffusion-controlled oxidation 
(Prahl et al., 1989). Remarkably, this severe degradation had no significant effect on the unsaturation pattern of the residual biomarker series. However, Flügge (1996) found that microbial induced degradation of an Emiliania huxleyi culture with initially low $\mathrm{U}_{37}^{\mathrm{k}}(0.23)$ values resulted in significantly higher $\mathrm{Uk}_{37}$ values.

Keil et al. (1994) studied the MAP f-turbidite for a sensitive tracer of oxygen-sensitive carbon. They found that pollen grains were completely degraded in the oxidized part of the turbidite. Microscopic determination revealed that the pollen in the unoxidized part of the turbidite were well preserved for at least 100 k.y. They also presented pollen data from the Pacific Northwest continental shelf, which suggest that oxic degradation can explain the decrease in OM with depth that is commonly observed in coastal sediments.

Here we report organic geochemical analyses of the insoluble $\mathrm{OM}$ (kerogen) present in MAP oxidized and unoxidized turbidites recovered during Leg 157. Kerogen represents by far the greatest part of the sedimentary organic matter ( $>95 \%$ by weight; Durand and Nicaise, 1980) and is, thus, an important OM fraction for study of the effect of postdepositional oxidation on OM preservation. Because of the insoluble macromolecular nature of the kerogen, we have analyzed the chemical composition of the kerogen by pyrolysis-gas chromatography-mass spectrometry. Pyrolysis of kerogen results in the thermal degradation of macromolecules into smaller chemical units. The identification and quantitation of these chemical units provides insight into the nature of the original organic matter and the differences in oxidation rates of different chemical entities in the kerogen.

\section{MATERIALS AND METHODS Samples}

The four turbiditic sequences studied are derived from Site 951B at $32^{\circ} 1.895{ }^{\prime} \mathrm{N}$ and $24^{\circ} 52.236^{\prime} \mathrm{W}(5436.8 \mathrm{~m}$ water depth; $351.6 \mathrm{~m}$ penetration) and Site $952 \mathrm{~A}$ at $30^{\circ} 47.449 \mathrm{~N}$ and $24^{\circ} 30.574{ }^{\prime} \mathrm{W}(5431.8$ $\mathrm{m}$ water depth; $425.9 \mathrm{~m}$ penetration). The entire cored section spans $13 \mathrm{Ma}$.

\section{Kerogen Isolation}

Samples were extensively ultrasonically extracted with a dichloromethane $(\mathrm{DCM}) /$ methanol $(\mathrm{MeOH})=7.5: 1$ mixture. After extraction, the residue was saponified to remove the ester-bound lipids by refluxing it with a solution of $1 \mathrm{~N}$ potassium hydroxide $(\mathrm{KOH})$ in $96 \%$ $\mathrm{MeOH}$ for $1 \mathrm{hr}$.The residue was ultrasonically extracted $(2 \times)$ with a mixture of $\mathrm{MeOH} /$ distilled water (1:1), twice with $\mathrm{MeOH}$, and three times with DCM. Finally, after saponification, the kerogens were isolated from the residues by removing the inorganic phase using a modification of the method reported by Durand and Nicaise (1980). Briefly, the residues were treated with $6 \mathrm{~N}$ hydrochloric acid $(\mathrm{HCl})$ for 2 $\mathrm{hr}$, washed with distilled water, and treated with HCL a second time for $16 \mathrm{hr}$. After centrifugation, the residues were washed with distilled water $(3 \times)$ before being treated with a mixture of $6 \mathrm{~N} \mathrm{HCl}$ and $40 \%$ hydrofluoric acid (1:3) for $2 \mathrm{hr}$. After the residues were washed with distilled water, a second demineralization step was performed

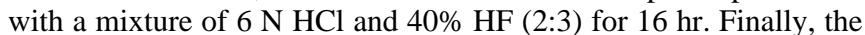
residues were treated once again with $6 \mathrm{~N} \mathrm{HCl}$ for $2 \mathrm{hr}$. All isolation procedures were performed in closed polytetrafluoroethylene (PTFE) bombs at $\sim 75^{\circ} \mathrm{C}$. The isolated kerogens were centrifuged and washed with distilled water until the supernatant was neutral. The supernatant was then ultrasonically extracted with $\mathrm{MeOH}(2 \times)$ and DCM $(2 \times)$. Before analysis, the kerogens were dried in a vacuum stove at $40^{\circ} \mathrm{C}$ for $24 \mathrm{hr}$.

\section{Flash Pyrolysis}

The isolated kerogens were analyzed by Curie point pyrolysis-gas chromatography (Py-GC) using an FOM-4LX Curie point pyrolysis unit directly connected to the injector of a Hewlett Packard 5890 Series II gas chromatograph. Samples were pressed on flattened ferromagnetic wires having a Curie temperature of $610^{\circ} \mathrm{C}$. Pyrolysis was conducted by inductive heating of the sample-coated wires within $0.15 \mathrm{~s}$ to the Curie temperature at which it was held for $10 \mathrm{~s}$. A Curie point high frequency generator (Fisher 9425) was used to induce the magnetic field. Separation of the pyrolysis products was achieved using a fused silica column $(25 \mathrm{~m} \times 0.32 \mathrm{~mm}$ I.D. $)$ coated with ChromPack CP-Sil 5 (film thickness $0.45 \mu \mathrm{m}$ ). Helium was used as carrier gas. The gas chromatograph, equipped with a cryogenic unit, was held at $0^{\circ} \mathrm{C}$ for $5 \mathrm{~min}$ before it was programmed at a rate of $3^{\circ} \mathrm{C} /$ min to $320^{\circ} \mathrm{C}$, where it was held for $10 \mathrm{~min}$. Py-GC-mass spectrometry (Py-GC-MS) was performed using the same conditions as above. The column was inserted directly into the electron impact ion source of a VG Autospec Ultima mass spectrometer operated at $70 \mathrm{eV}$, with a mass range of $m / z, 40-800$ and a cycle time of $1.8 \mathrm{~s}$. Compounds were identified based on their mass spectra and retention times; identifications were also based partly on comparisons with published mass spectra and relative retention time data (Hartgers et al., 1992; Ioppolo et al., 1992; Sinninghe Damsté et al., 1988).

\section{Relative Quantitation}

Relative amounts of the individual compounds in the pyrolysates were determined by integrating individual peak areas from summed mass chromatograms using characteristic $\mathrm{m} / \mathrm{z}$ values. These characteristic mass fragments represent only part of the total mass spectrum. To correct for this, peak areas were multiplied by correction factors (Hartgers et al., 1994b), which were obtained from spectra of authentic standards and are representative of each compound class.In addition to peak-area correction factors, we determined correction factors for alkan-2-ones and 6,10,14-trimethyl-2-pentadecanone (Table 1).

\section{RESULTS}

Twelve samples from four turbidites (Table 2) were selected for study. For each studied turbidite, we analyzed one sample in the oxidized part and two in the unoxidized part (Fig. 1). The TOC weight percentages (Table 2) show a large decrease in the oxidized samples relative to the unoxidized samples, which have nearly uniform TOC values. The homogeneity of the unoxidized samples is also illustrated by the identical $\delta^{13} \mathrm{C}$ values of the TOC in both unoxidized samples. The oxidized samples are $0.65 \%$ o to $2.2 \%$ o lighter than the oxidized samples, which is consistent with data by McArthur et al. (1992) and Prahl et al. (1997) for the MAP a-, e-, and f-turbidites. Turbidite $18 x$ shows a relatively small decrease of $0.65 \%$, whereas turbidite $23 \mathrm{x}$ is $2.2 \%$ lighter. As part of the kerogen isolation procedure, the free and ester-bound lipids from the turbidite samples had to be removed. The

Table 1. Characteristic $\mathrm{m} / \mathrm{z}$ values and correction factors used to calculate the relative abundances and interval distribution patterns of the alkan-2ones and 6, 10, 14-trimethyl-2-pentadecanone in pyrolysates of MAP turbidites.

\begin{tabular}{lll}
\hline \multicolumn{1}{c}{ Compound class } & \multicolumn{2}{c}{ Characteristic fragments } \\
\hline $\mathrm{C}_{6}$ to $\mathrm{C}_{27}$ methylketones & $54+55+57+58+59+67+69+71+81+82+83+95+96+97+109+110+113+119+124+125+127+134+138+142$ \\
$6,10,14$-trimethyl-2-pentadecanone & $55+56+57+58+59+69+70+71+81+82+83+84+85+95+96+97+109+110+111+112+113+123+124+138+165+210+250$ & 3.1 \\
\hline
\end{tabular}


Table 2. Some characteristics of the studied samples.

\begin{tabular}{|c|c|c|c|c|c|}
\hline $\begin{array}{l}\text { Core, section, } \\
\text { interval }(\mathrm{cm})\end{array}$ & $\begin{array}{l}\text { Depth } \\
\text { (mbsf) }\end{array}$ & $\begin{array}{l}\text { TOC } \\
(\%)\end{array}$ & $\begin{array}{l}\delta^{13} \mathrm{C} \\
(\% \circ)\end{array}$ & $\begin{array}{c}\text { Free lipid yield } \\
\left(\mathrm{mg} \cdot \mathrm{g}^{-1} \text { dry weight }\right)\end{array}$ & $\begin{array}{l}\text { Bound lipid yield } \\
\left(\mathrm{mg} \cdot \mathrm{g}^{-1} \text { dry weight }\right)\end{array}$ \\
\hline \multicolumn{6}{|l|}{ 157-951B- } \\
\hline $3 X-4,79-84$ & 279.59 & 0.18 & -22.7 & 0.06 & 0.06 \\
\hline $3 \mathrm{X}-4,93-101$ & 279.73 & 1.41 & -20.8 & 0.51 & 0.24 \\
\hline $3 X-4,107-117$ & 279.87 & 1.33 & -20.9 & 0.50 & 0.38 \\
\hline \multicolumn{6}{|l|}{$157-952 \mathrm{~A}-$} \\
\hline $9 \mathrm{H}-5,50-57$ & 82.8 & 0.14 & -22.3 & 0.04 & 0.04 \\
\hline $9 \mathrm{H}-5,94-104$ & 83.24 & 0.73 & -20.6 & 0.23 & 0.18 \\
\hline $9 \mathrm{H}-6,10-20$ & 83.55 & 0.78 & -20.5 & 0.18 & 0.18 \\
\hline $18 \mathrm{X}-3,101-111$ & 159.61 & 0.45 & -20.5 & 0.06 & 0.04 \\
\hline $18 \mathrm{X}-3,121-131$ & 159.81 & 1.64 & -19.9 & 0.49 & 0.41 \\
\hline $18 \mathrm{X}-4,55-64$ & 160.65 & 1.53 & -19.8 & 0.45 & 0.41 \\
\hline $23 X-5,46-52$ & 210.26 & 0.21 & -22.1 & 0.06 & 0.17 \\
\hline $23 X-5,74-84$ & 210.54 & 1.16 & -20.0 & 0.30 & 0.31 \\
\hline $23 X-6,31-41$ & 211.61 & 1.06 & -19.8 & 0.41 & 0.25 \\
\hline
\end{tabular}

Note: Depth and total organic carbon (TOC) after De Lange (Chap. 33, this volume).

gravimetric yields of these lipids (Table 2) roughly follow the TOC content; that is, the low TOC values of the oxidized samples are accompanied by low extraction yields of free and ester-bound lipids. The extent to which these lipids are degraded is, considering some analytical scatter, similar to that of the TOC $(\sim 80 \%)$. For the neutral sugars, total hydrolyzable amino acids, lignin phenols, some marine phytoplankton biomarkers, and plantwax $n$-fatty acids, this was also reported by Prahl et al. (1997) for the MAP f-turbidite.

\section{General Description of the Pyrolysates}

The isolated kerogens were studied by flash pyrolysis GC and PyGC-MS. Typical flash pyrolysates of isolated MAP turbidite kerogens are shown in Figure 2. The upper panel shows the total ion current (TIC) traces of the pyrolysate of an oxidized sample, and the bottom panel shows two TIC traces of unoxidized counterparts. The homogeneity of the original turbiditic OM is illustrated on the molecular level by the two virtually identical TIC traces of the latter two samples. The pyrolysates contain several series of compounds. The major compound classes constituting the pyrolysates of both the oxidized and unoxidized MAP turbidites are $n$-alkanes, $n$-alk-1-enes, alkylbenzenes, alkylthiophenes, alkylphenols, alkylnaphthalenes, isoprenoid alkanes and alkenes, alkan-2-ones, and alkylindenes. It is apparent from the three TIC traces in Figure 2, however, that the relative abundances and distributions of these compound classes vary significantly. For example, the pyrolysates of the kerogens of the unoxidized samples have a high abundance of 1,2,3,4-tetramethylbenzene, a $\mathrm{C}_{13}$ isoprenoid alkane, a monounsaturated $\mathrm{C}_{14}$ isoprenoid alkene, and prist-1-ene, whereas the pyrolysate of the oxidized turbidite layer is virtually devoid of these compounds.

Differences between the oxidized and unoxidized part of the turbidite are clearly revealed by the relative quantitation results shown in Figure 3. The relative abundance of the various compound classes shown in this figure have been obtained by integration of the individual peak areas from summed mass chromatograms using characteristic $\mathrm{m} / \mathrm{z}$ values. Although it is not yet clear how the absolute abundances of these eight compound classes vary, it is possible to compare their relative changes in abundance. The $n$-alkanes, $n$-alk-1-enes, isoprenoids, and alkylthiophenes show the largest variations in relative abundance. A sharp decrease of the isoprenoid and alkylthiophene percentages and a similar pronounced increase in $n$-alkane and $n$-alk1-ene percentages from the unoxidized to the oxidized samples can be seen in all four turbidites studied (Fig. 3). Turbiditic sequences $23 \mathrm{x}$ and $9 \mathrm{~h}$ show the largest increase in relative abundance of the $n$ alkanes and $n$-alk-1-enes. The decrease in isoprenoids is most pronounced in turbidites $23 \mathrm{x}$ and $3 \mathrm{x}$. Turbidite $18 \mathrm{x}$ shows the least pronounced changes in $n$-alkane, $n$-alk-1-ene, and isoprenoid percentages, consistent with the smallest reduction in TOC content $(72 \%$;

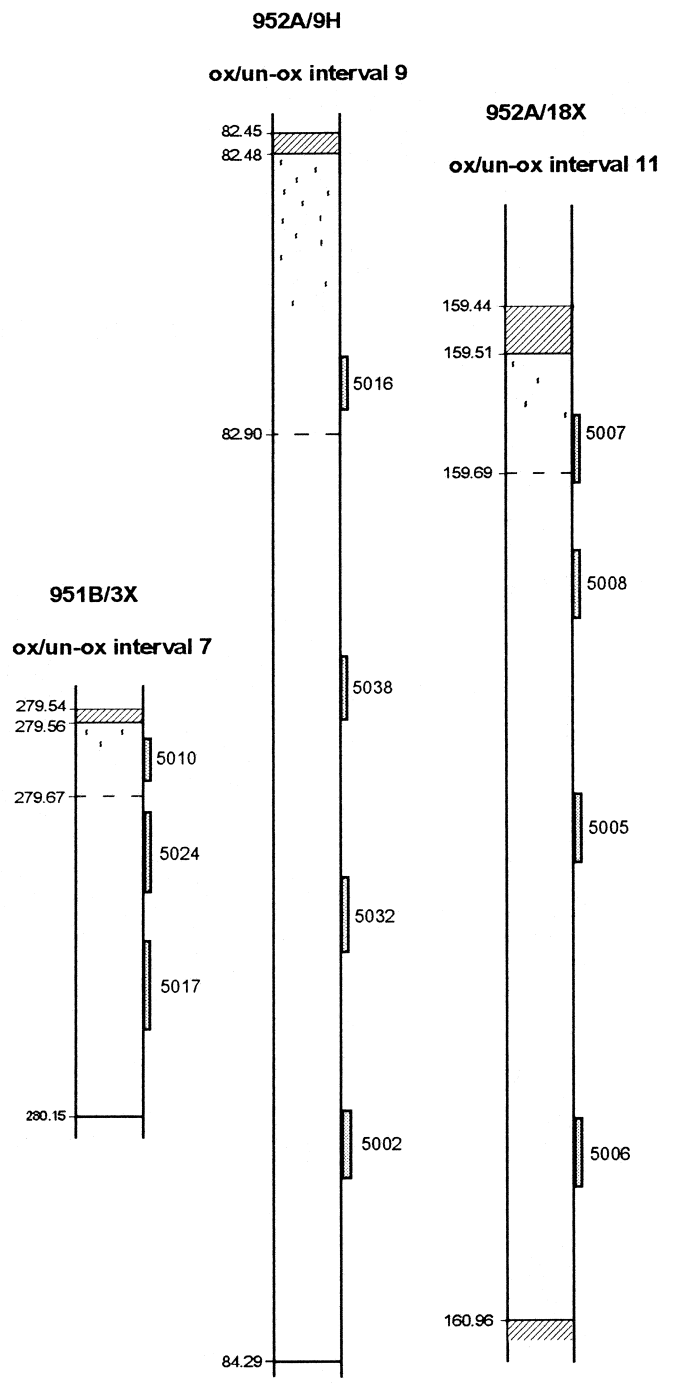

Figure 1. Position of the samples in the turbidite intervals. Analyzed samples $3 \mathrm{X}$ (5010, 5024, and 5017), 9H (5016, 5038, and 5002), and 18X (5007, 5008, and 5006) are after De Lange (Chap. 33, this volume).

Table 2) and change in $\delta^{13} \mathrm{C}(0.6 \%$; Table 2$)$. The other studied compound classes do not show a marked increase or decrease in relative abundance across the redox front in Figure 3. Below we will present a more detailed picture of the internal distributions of the various compound classes.

\section{$n$-Alkanes and $\boldsymbol{n}$-Alk-1-enes and Isoprenoids}

Figure 4 shows the internal distributions of $n$-alkanes, $n$-alk-1enes and isoprenoids in an oxidized and unoxidized sample from turbidite $3 \mathrm{x}$ in summed mass chromatograms of $m / z 55+57$. The $n$ alkane and $n$-alk-1-ene series range maximal from $\mathrm{C}_{7}$ to $\mathrm{C}_{32}$, and the isoprenoids are represented by a specific number of isomers, as indicated in Figure 5. The internal distributions of the $n$-alkanes and $n$ alk-1-enes and isoprenoids of samples from turbidite $23 \mathrm{x}$ are presented in three bar charts, which were obtained by integration of appropriate peaks in $\mathrm{m} / z 55+57$ mass chromatograms. Not all distributions of n-alkanes and $n$-alk-1-enes extend to $\mathrm{C}_{32}$, and this phenomenon seems to correlate with the extent of TOC loss. Our data reveal, however, that in all cases the internal distributions of the two unoxidized samples of each turbidite are identical (e.g., Fig. 5). In all oxidized 


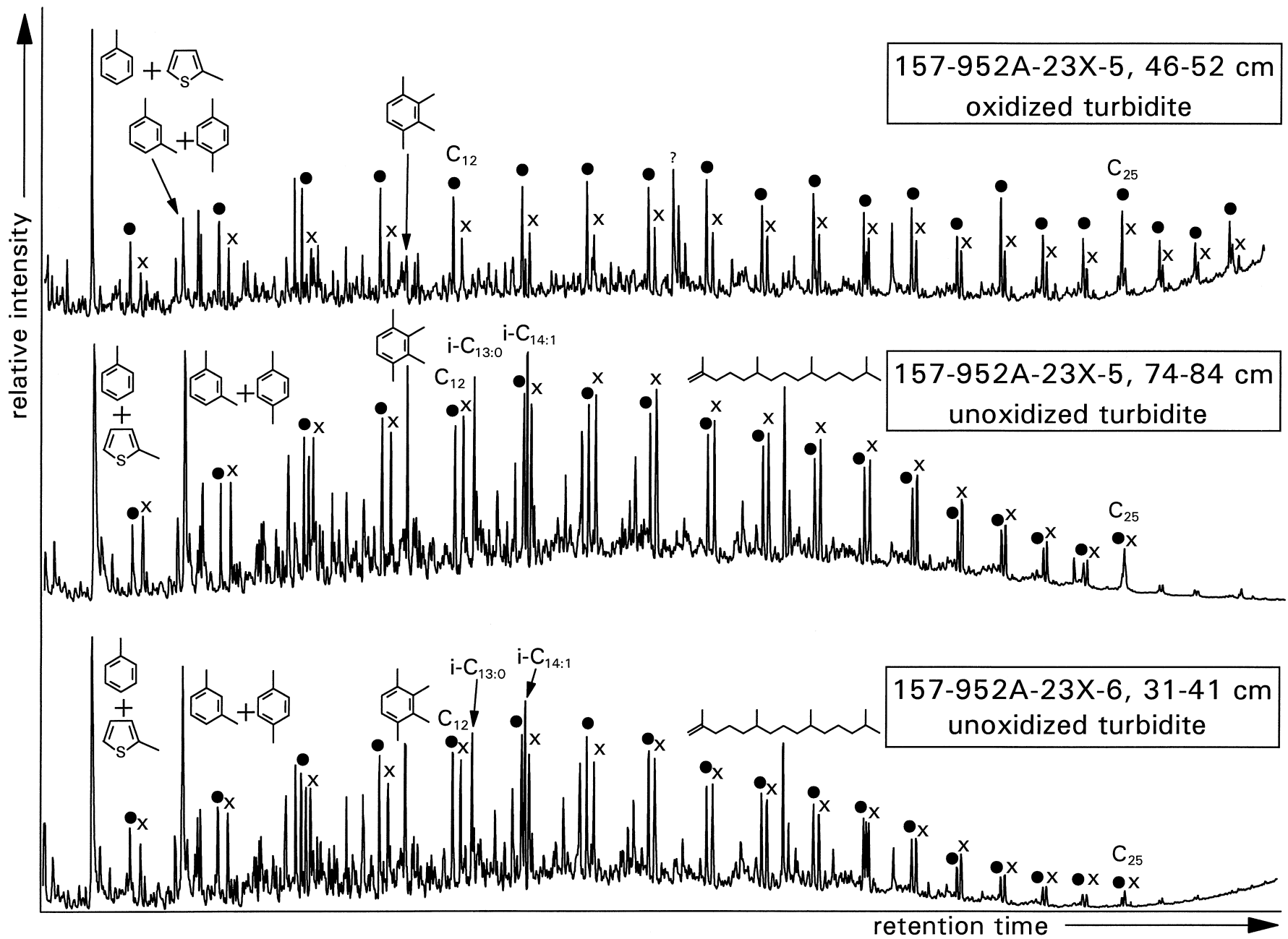

Figure 2. Py-GC-MS traces of turbidite $23 \mathrm{X}$ kerogen samples. $\mathrm{X}=n$-alkanes, solid circles $=n$-alk-1-enes, and $\mathrm{i}=\mathrm{isoprenoids}$. Isoprenoid alkanes and alkenes are denoted by $\mathrm{i}-\mathrm{C}_{\mathrm{x}: \mathrm{y}}$, where $\mathrm{x}=$ the number of carbon atoms and $\mathrm{y}=$ the number of double bonds. ? in top row $=$ unknown constituent.

turbidites, the $n$-alk-1-enes are more abundant relative to the $n$ alkanes than in the unoxidized turbidites. This is mathematically expressed in Table 3 by using the unsaturation index (USI), which is defined as

$$
U S I=\frac{[n-\text { alkanes }]}{[n-\text { alkanes }]+[n-\text { alk }-1-\text { enes }]}
$$

The relative abundances of the isoprenoids in all of the pyrolysates of the oxidized turbidites show a sharp decrease of all isomers. Turbiditic sequence $23 \mathrm{x}$ and $3 \mathrm{x}$, in particular, are characterized by large relative decreases of isoprenoids. Turbidite $18 \mathrm{x}$ shows a relatively small decrease of isoprenoid percentages, which is apparent from the total isoprenoid/total ( $n$-alkanes $+n$-alk-1-enes) ratio in Table 3 . The relative abundances of saturated acyclic isoprenoids decreased more than their unsaturated counterparts, which is in accordance with the already-mentioned increase in unsaturation in the $n$-alkane and $n$-alk-1-ene distribution. All studied turbidites exhibit a large relative decrease of prist-1-ene upon oxidation. This decrease is not accompanied by a similar decrease of prist-2-ene, as can be seen from the prist-1-ene/(prist-1-ene + prist-2-ene) ratio in Table 3 . The largest drop in this ratio is exhibited by turbidite $9 \mathrm{~h}$ and, to a lesser degree, by turbidites $23 \mathrm{x}$ and $3 \mathrm{x}$. Turbidite $18 \mathrm{x}$ shows the smallest drop in the pristene ratio.

In summary, some differences between the internal distributions of the unoxidized and oxidized samples can be seen among the four studied turbidites. However, the general trend is the same: an increase in the $n$-alk-1-enes relative to the $n$-alkanes and a drastic decrease of the isoprenoids in comparison with the ( $n$-alkanes $+n$-alk-1-enes).

\section{Alkan-2-ones}

Figure 6 represents the internal distributions of the alkan-2-ones in turbidite $23 \mathrm{x}$ in three bar charts, which were obtained by integrating the appropriate peaks in $\mathrm{m} / \mathrm{z}$ 58-mass chromatograms. Similar to the $n$-alkane and $n$-alk-1-ene series, the internal distributions of the alkan-2ones series do not always extend over the full $\mathrm{C}_{6}-\mathrm{C}_{27}$ range. In addition to these unbranched ketones, the pyrolysates also contained $6,10,14$ trimethyl-2-pentadecanone, an isoprenoid ketone. This ketone showed a pronounced relative decrease in the oxidized samples of all studied turbidites.

\section{Alkylbenzenes}

Figure 7 shows the internal distributions of the $\mathrm{C}_{0}-\mathrm{C}_{4}$ alkylated benzenes in two summed mass chromatograms $(\mathrm{m} / \mathrm{z}, 78+91+92+$ $105+106+119+120+133+134+147+148$ ) for turbidite $3 x$. The numbers in the figure refer to compounds listed in Table 4 . The internal distributions of the $\mathrm{C}_{0}-\mathrm{C}_{4}$ alkylated benzenes in turbidite $23 \mathrm{x}$ are shown in three bar charts (Fig. 8), which were obtained by integration of appropriate peaks in the above mass chromatograms. The pyroly- 


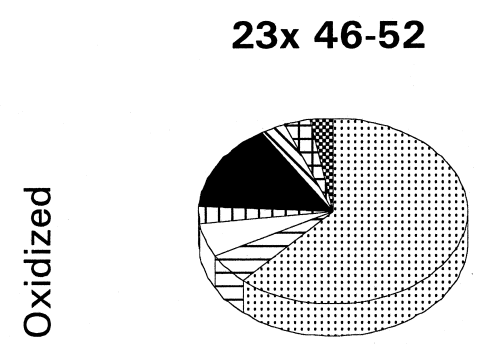

$3 \times 79-84$

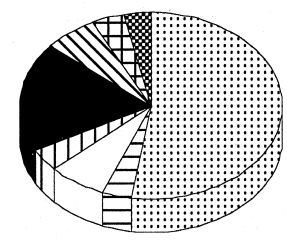

9H 50-57

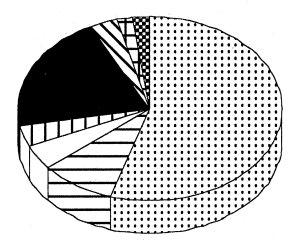

$18 \times 101-111$

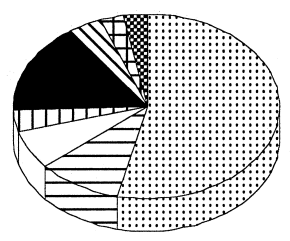

$23 \times 74-84$

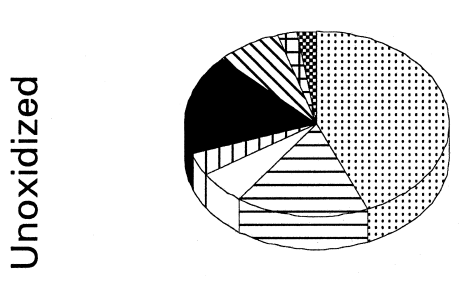

$23 \times 31-41$

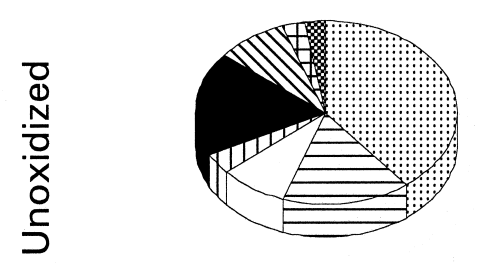

3x 93-101

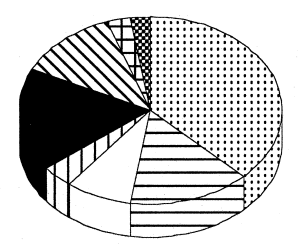

$3 \times 107-117$

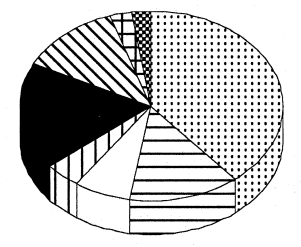

9H 94-104

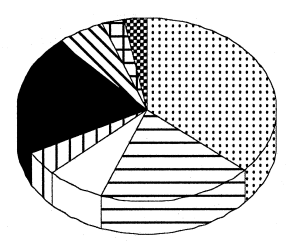

9H $10-20$

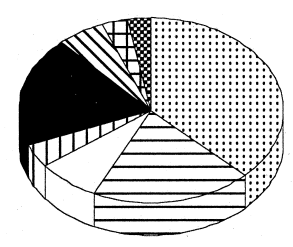

$18 \times 121-131$

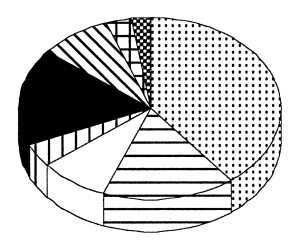

$18 \times 55-64$

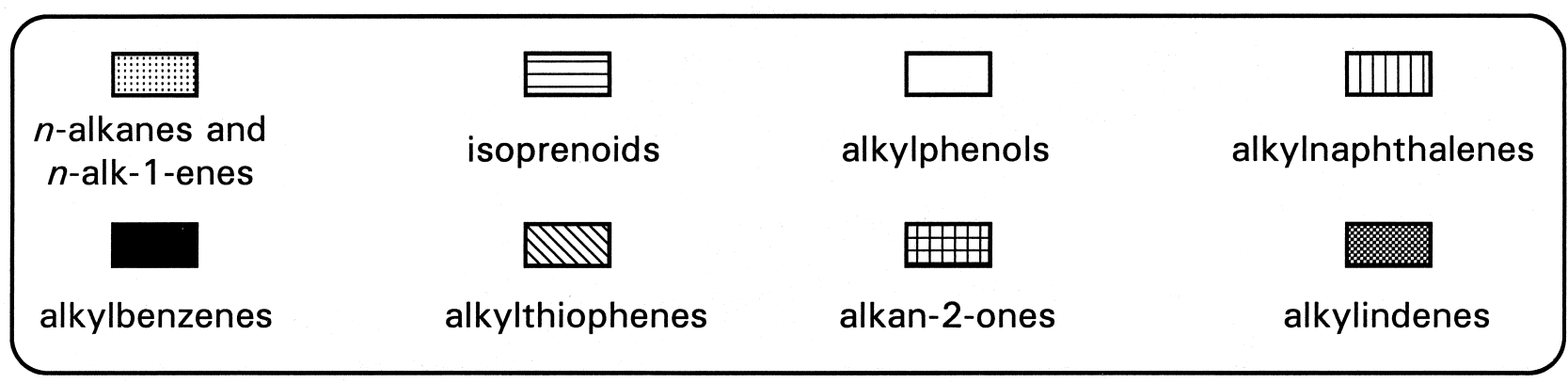

Figure 3. Pie charts showing the relative abundances of the various compound classes in all four turbidite sequences studied.

sates of the oxidized turbidites are characterized by a relative increase in less alkylated benzenes, such as benzene and toluene, as is illustrated by the increase of the alkylation index (AI) of the benzenes (Table 3). This relative increase is accompanied by a large decrease in, for example, $m$-, $p$-xylene and especially 1,2,3,4-tetramethylbenzene (Table 3). A typical feature of all distributions is the high relative abundance of the 1-methyl-2- $n$-alkyl-benzenes and $n$-propylbenzene in the oxidized turbidites. For $o$-xylene and 1-methyl-2-ethylbenzene, this is illustrated by the increase of the $o$-xylene/total $\mathrm{C}_{2}$ alkylated benzenes and 1-methyl-2-ethylbenzene/total $\mathrm{C}_{3}$ alkylated benzenes ratios (see Table 3 ) for the oxidized samples. The third alkylbenzene in this series (1-methyl-2-propylbenzene) does not show a similarly consistent enrichment in the oxidized samples (Table 3).

\section{Alkylthiophenes}

Three summed mass chromatograms in Figure 9 reveal the internal distribution of $\mathrm{C}_{0}-\mathrm{C}_{5}$ alkylated thiophenes in the pyrolysates of turbidite $23 x$. These were obtained by integration of appropriate peaks in $\mathrm{m} / \mathrm{z} 84+97+98+111+112+125+126+139+140+$ $153+154$ mass chromatograms. The numbers in the figure refer to 


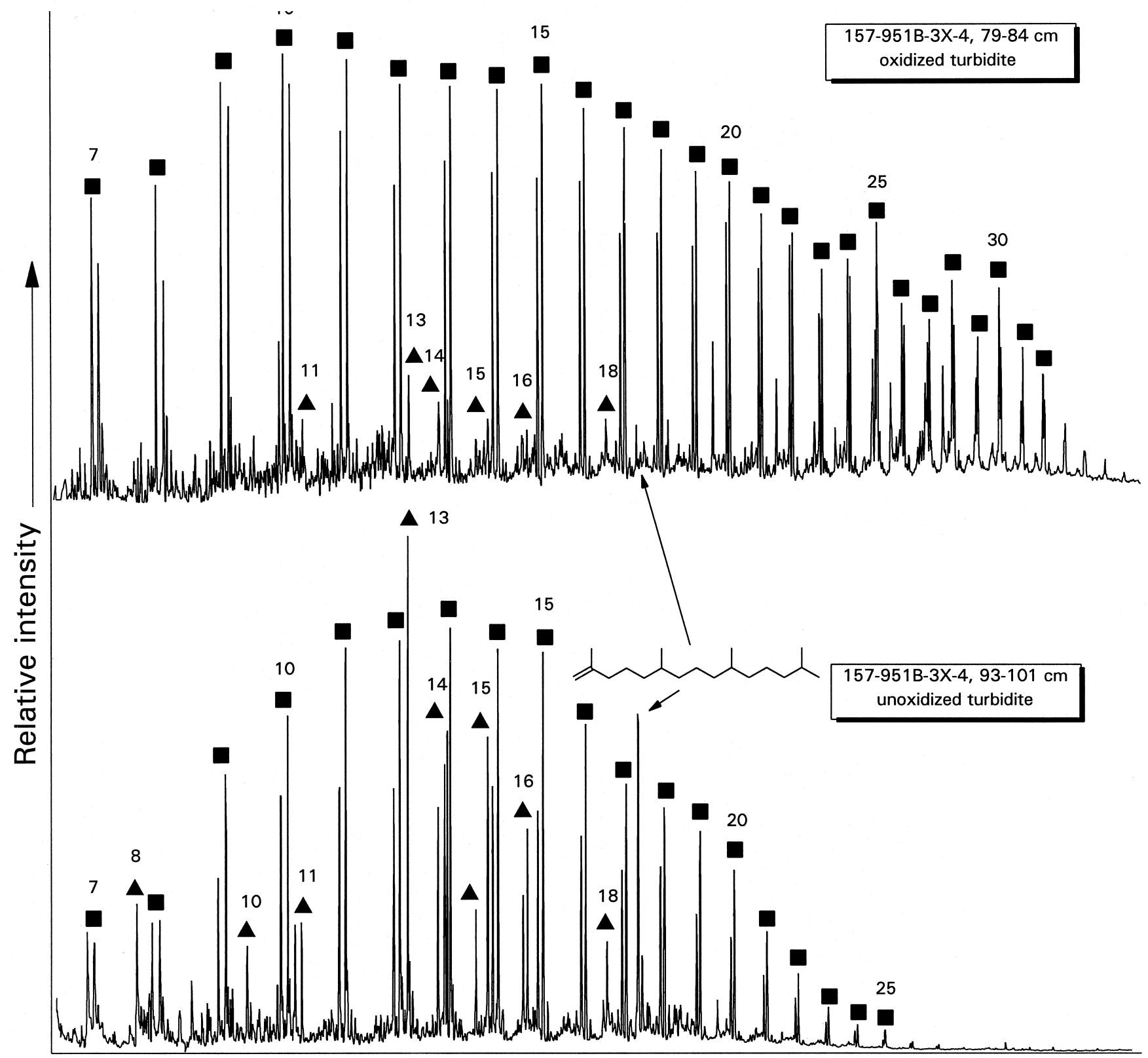

Figure 4. Summed mass chromatograms of $m / z, 55+57$, showing the internal distributions of the $n$-alkanes, $n$-alk-1-enes, isoprenoid alkanes and alkenes, prist1 -ene, and prist-2-ene of turbidite $3 \mathrm{X}$ kerogen samples. Solid squares $=n$-alkane and $n$-alk-1-ene doublets. Solid triangles $=$ isoprenoid alkanes and alkenes. Numbers $=$ the number of carbon atoms of the $n$-alkanes and $n$-alk-1-enes and isoprenoids.

compounds listed in Table 5. In contrast to the alkylbenzenes, alkylthiophene distributions are not changed to a large extent. The alkylation index for the thiophenes in Table 3 illustrates that the less alkylated thiophenes are not greatly enriched in the oxidized turbidite samples, as was the case for the alkylbenzenes.

\section{Alkylphenols}

Figure 10 reveals the internal distributions of the $\mathrm{C}_{0}-\mathrm{C}_{4}$ alkylphenols in the kerogen pyrolysates of turbidite $3 \mathrm{x}$. The numbers in the figure refer to compounds listed in Table 6 . The bar charts were obtained by integration of appropriate peaks in $\mathrm{m} / z, 94+107+108+$
$121+122+135+136$ mass chromatograms. Differences between the oxidized and unoxidized samples with respect to the internal distribution are not as apparent as with, for instance, the $n$-alkane and $n$ alk-1-ene distributions. Nevertheless, all oxidized samples, especially turbiditic sequences $23 \mathrm{x}$ and $3 \mathrm{x}$, are relatively more enriched in $\mathrm{C}_{0}$ and $\mathrm{C}_{1}$ alkylated phenols (Table 3; $\mathrm{AI}$ [phenols]) compared to the unoxidized samples.

\section{Alkylnaphthalenes and Alkylindenes}

Alkylnaphthalene distributions in the oxidized samples are characterized by a higher abundance of $\mathrm{C}_{0}$ to $\mathrm{C}_{1}$ alkylated naphthalenes 

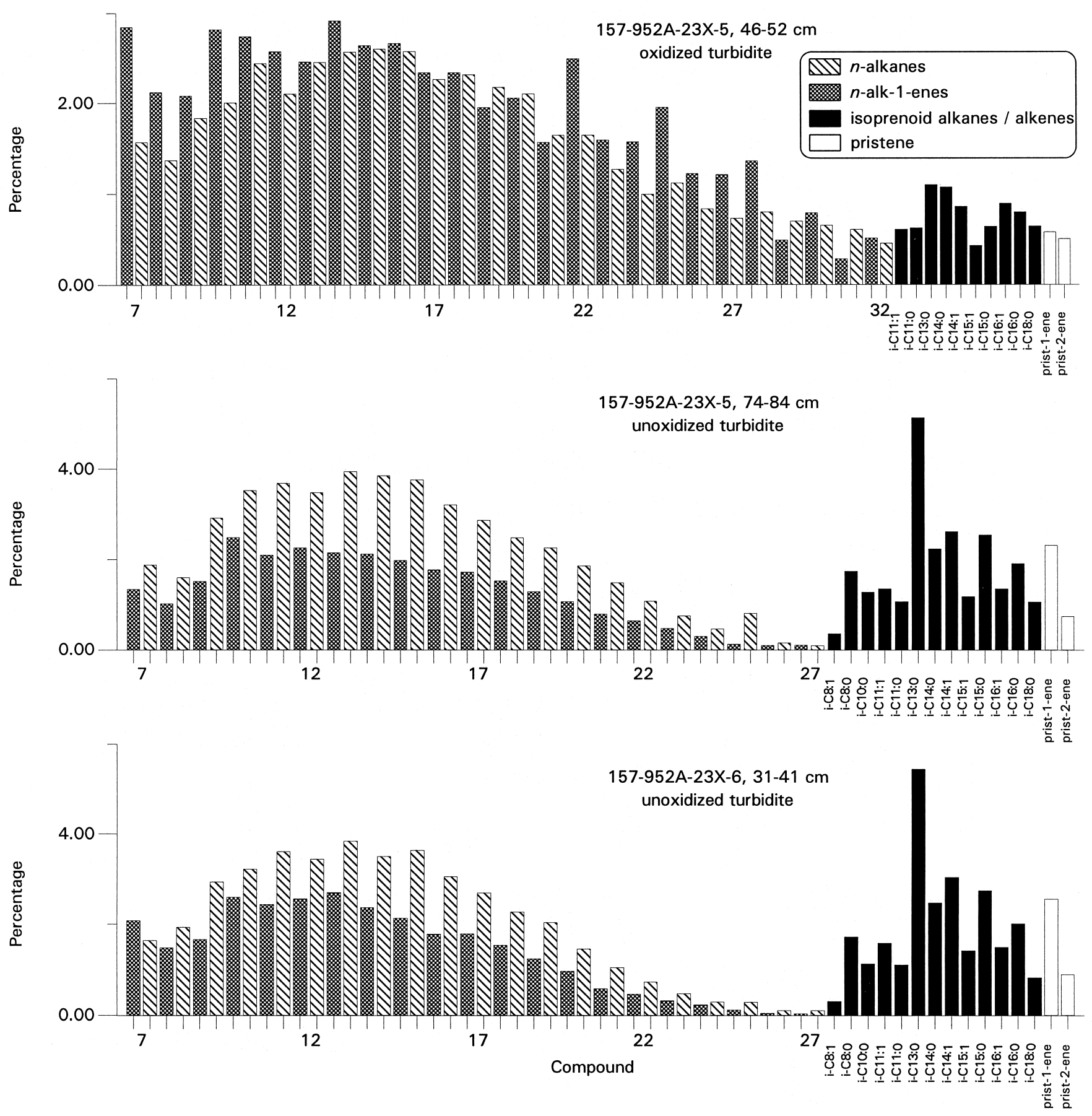

Figure 5. Bar plots showing the internal distributions of the $n$-alkanes, $n$-alk-1-enes, isoprenoid alkanes and alkenes, prist-1-ene, and prist-2-ene of turbidite 157-952A-23X kerogen samples. The numbers on the x-axis indicate the total number of carbon atoms in the $n$-alkanes and $n$-alk-1-enes. Isoprenoid alkanes and alkenes are denoted by $\mathrm{i}-\mathrm{C}_{\mathrm{x}: \mathrm{y}}$, where $\mathrm{i}=$ isoprenoids, $\mathrm{x}=$ the number of carbon atoms, and $\mathrm{y}=$ the number of double bonds.

compared with the unoxidized samples This can be seen from the alkylation index in Table 3 (AI [naphthalenes]). The large increase of naphthalene relative to the other alkylated naphthalenes is especially striking.

The alkylindene internal distributions are all more or less identical among the studied turbidites. There is also no significant difference in internal distributions between the oxidized and unoxidized samples.

\section{DISCUSSION}

\section{Homogeneity of the Original Turbidite Material}

The original turbiditic material from the MAP samples is very homogeneous in composition. The identical TOC and $\delta^{13} \mathrm{C}$ values are the first clues pointing in this direction. Figure 3 provides additional evidence, at the molecular level, for this finding; the relative abundance of the various compound classes in the unoxidized sample 
Table 3. Ratios of selected compounds calculated from the relative quantitation results.

\begin{tabular}{|c|c|c|c|c|c|c|c|c|c|c|c|c|c|}
\hline Site & Sample code & Redox state & AI (phenols) & AI (naphthalenes) & AI (benzenes) & AI (thiophenes) & $\operatorname{Pr} 1 / \operatorname{Pr} 1+\operatorname{Pr} 2$ & TMB $\%$ & $o$-xyl./tot. C2 & 1-me-2-et./tot. C3 & 1-me-2-pr.tot. C4-TMB & USI & Isopren./tot. $n$-alk. \\
\hline $951 \mathrm{~B}$ & $3 \mathrm{X}, 79-84$ & Oxidized & 0.63 & 0.53 & 0.48 & 0.33 & 0.55 & 2.5 & 0.36 & 0.18 & 0.14 & 0.4 & 0.07 \\
\hline $951 \mathrm{~B}$ & $3 X, 93-101$ & Unoxidized & 0.43 & 0.30 & 0.21 & 0.29 & 0.78 & 13.3 & 0.18 & 0.08 & 0.10 & 0.5 & 0.40 \\
\hline $951 \mathrm{~B}$ & $3 \mathrm{X}, 107-117$ & Unoxidized & 0.40 & 0.29 & 0.23 & 0.32 & 0.69 & 13.2 & 0.22 & 0.08 & 0.13 & 0.5 & 0.35 \\
\hline $952 \mathrm{~A}$ & $9 \mathrm{H}, 50-57$ & Oxidized & 0.56 & 0.55 & 0.43 & 0.44 & 0.38 & 3.8 & 0.30 & 0.15 & 0.12 & 0.4 & 0.17 \\
\hline $952 \mathrm{~A}$ & $9 \mathrm{H}, 94-104$ & Unoxidized & 0.47 & 0.31 & 0.32 & 0.40 & 0.73 & 9.5 & 0.22 & 0.09 & 0.14 & 0.5 & 0.53 \\
\hline $952 \mathrm{~A}$ & $9 \mathrm{H}, 10-20$ & Unoxidized & 0.45 & 0.31 & 0.27 & 0.36 & 0.72 & 10.1 & 0.22 & 0.10 & 0.13 & 0.5 & 0.52 \\
\hline $952 \mathrm{~A}$ & $18 \mathrm{X}, 101-111$ & Oxidized & 0.63 & 0.43 & 0.35 & 0.37 & 0.73 & 5.3 & 0.29 & 0.14 & 0.19 & 0.4 & 0.19 \\
\hline $952 \mathrm{~A}$ & $18 \mathrm{X}, 121-131$ & Unoxidized & 0.49 & 0.26 & 0.24 & 0.34 & 0.78 & 12.3 & 0.23 & 0.08 & 0.12 & 0.5 & 0.41 \\
\hline $952 \mathrm{~A}$ & $18 \mathrm{X}, 55-64$ & Unoxidized & 0.42 & 0.28 & 0.23 & 0.35 & 0.76 & 12.1 & 0.24 & 0.08 & 0.13 & 0.5 & 0.44 \\
\hline $952 \mathrm{~A}$ & $23 X, 46-52$ & Oxidized & 0.66 & 0.45 & 0.47 & 0.46 & 0.53 & 3.2 & 0.32 & 0.14 & 0.13 & 0.3 & 0.09 \\
\hline $952 \mathrm{~A}$ & $23 \mathrm{X}, 74-84$ & Unoxidized & 0.41 & 0.29 & 0.24 & 0.38 & 0.76 & 11.5 & 0.25 & 0.11 & 0.14 & 0.5 & 0.37 \\
\hline $952 \mathrm{~A}$ & $23 \mathrm{X}, 31-41$ & Unoxidized & 0.51 & 0.30 & 0.28 & 0.31 & 0.74 & 10.3 & 0.23 & 0.10 & 0.10 & 0.5 & 0.40 \\
\hline
\end{tabular}

Notes: $\mathrm{AI}=$ alkylation index, calculated as $\mathrm{C}_{0}+\mathrm{C}_{1} / \mathrm{C}_{0}+\mathrm{C}_{1}+\mathrm{C}_{2}+\mathrm{C}_{3}+\mathrm{C}_{4}+\mathrm{C}_{5}\left(\mathrm{C}_{5}\right.$ only thiophenes); $\operatorname{Pr} 1 / \operatorname{Pr} 1+\operatorname{Pr} 2=$ prist-1-ene/prist-1-ene + prist-2-ene; TMB\% = percentage of 1,2,3,4-tetramethylbenzene of total alkylbenzenes; $o$-xyl./ tot.C2 $=o$-xylene/ total $C_{2}$ alkylated benzenes; 1 -me-2et./tot.C3 $=1$-methyl-2-ethylbenzene/total $C_{3}$ alkylated benzenes; 1 -me.2-pr./tot.C4-TMB $=1$-methyl-2-propylbenzene/total $C_{4}$ alkylated benzenes; USI = unsaturation index; Isopren./tot. $n$-alk. $=$ isoprenoid alkanes and alkenes/total $n$-alkanes $+n$-alk-1-enes. 

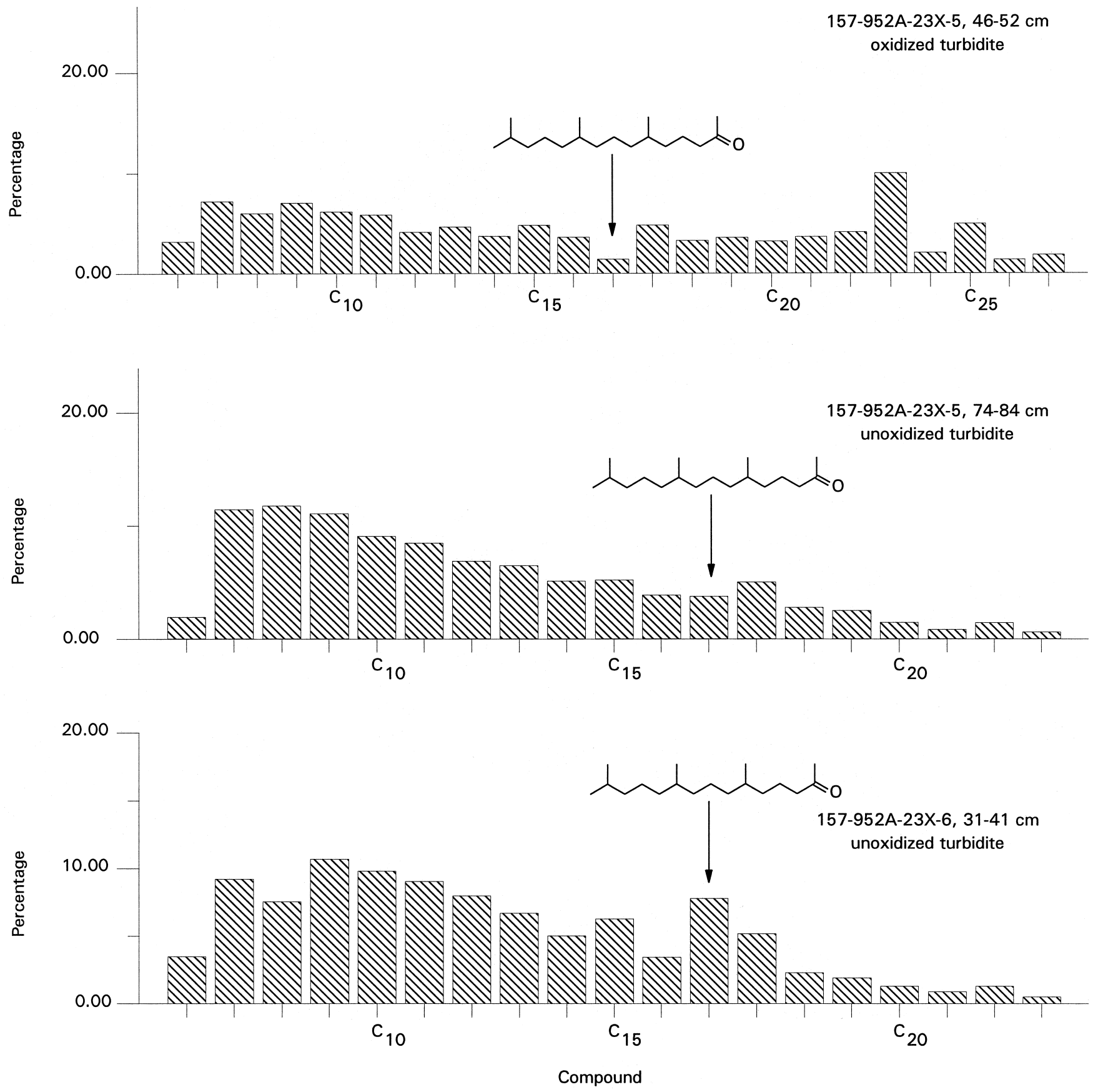

Figure 6. Bar plots showing the internal distributions of the alkan-2-ones $(\mathrm{m} / \mathrm{z}$ 58) of turbidite 157-952A-23X kerogen samples. The numbers on the $\mathrm{x}$-axis indicate the total number of carbon atoms in the alkan-2-ones.

pairs is, within analytical error, identical. Finally, even the internal distributions of the various compound classes are often very similar between the two unoxidized samples per turbidite, (e.g., Figs. 4, 6, 7, 10). The initial homogeneity of the original turbiditic organic matter creates the ideal starting conditions for the study of the effect of oxidation by molecular oxygen on the chemical composition of the organic matter.

\section{Sources of the Pyrolysis Products}

The $n$-alkane and $n$-alk-1-ene doublets in the pyrolysates typically reflect the presence in the kerogens of macromolecules containing long polymethylenic chains. It is now well known that certain microalgae, especially Chlorophyceae and Eustigmatophyceae, biosynthesize nonhydrolyzable and highly aliphatic macromolecules called algaenan, which comprise the outer cell walls (Largeau et al., 1984; Goth et al., 1988; Derenne et al., 1992; De Leeuw and Largeau, 1993; Gelin et al., 1996). These algaenans become relatively enriched in sedimentary OM, since they are probably the most resistant to microbial degradation.

The origin of most of the isoprenoid alkanes and alkenes is less clear, but they may be derived from an isoprenoid algaenan. Derenne et al. (1989, 1990a) and Behar et al. (1995) reported such an isoprenoid algaenan in the lacustrine alga Botryococcus braunii, $L$ race, 


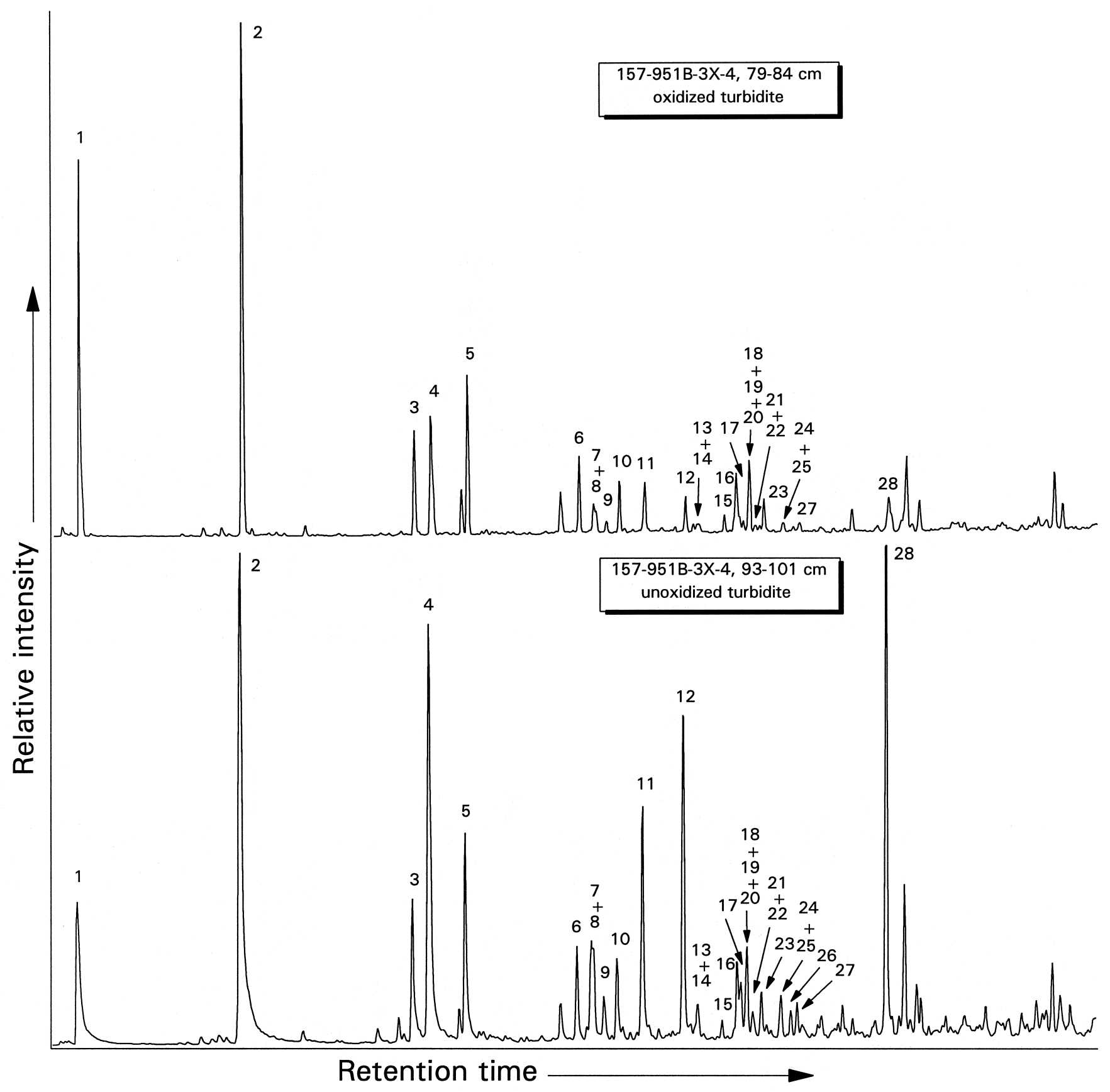

Figure 7. Summed mass chromatograms $(\mathrm{m} / \mathrm{z}, 78+91+92+105+106+119+120+133+134+147+148)$ of flash pyrolysates of turbidite $157-951 \mathrm{~B}-3 \mathrm{X}$, illustrating the internal distributions of the $\mathrm{C}_{0}-\mathrm{C}_{4}$ alkylated benzenes. The numbers refer to compounds listed in Table 4 .

which is based on $\mathrm{C}_{40}$ isoprenoid chains with lycopane-type skeletons. Pyrolysis of the algaenan isolated from this alga resulted in the following typical pyrolysis products: saturated and unsaturated isoprenoid hydrocarbons, isoprenoid aromatic hydrocarbons, prist-1ene, prist-2-ene, and 6,10,14-trimethyl-2-pentadecanone. It is not yet clear what the origin of the isoprenoids in the pyrolysates of marine kerogens is. A contribution from the lacustrine alga Botryococcus braunii, $L$ race, transported to the source area of the MAP turbidite seems unlikely. Considering the high relative abundance of the isoprenoids in the unoxidized samples, it may suggest an as yet unknown marine algal source.
Prist-1-ene can be derived from tocopherols (Goossens et al., 1984), but the origin for prist-2-ene is still unknown. However, it has been proposed that prist-2-ene can be formed through a presumably clay-catalyzed isomerization of prist-1-ene upon pyrolysis (Regtop et al., 1986). This formation mechanism seems unlikely because the studied kerogens are thoroughly isolated from the inorganic matrix, effectively removing the matrix effect of clay minerals.

Alkan-2-ones are found regularly in pyrolysates of kerogens that are composed primarily of algaenans. The ketones can be formed, upon pyrolysis, by homolytic cleavage of ether bonds (Gelin et al., 1993, 1994), which participate in the macromolecular network of 
Table 4. Alkylbenzenes identified in kerogen pyrolysates.

\begin{tabular}{ll}
\hline Peak & \multicolumn{1}{c}{ Compound } \\
\hline 1 & Benzene \\
2 & Toluene \\
3 & Ethylbenzene \\
4 & $m$-, p-xylene \\
5 & $o$-xylene \\
6 & $n$-propylbenzene \\
7 & 1-methyl-3-ethylbenzene \\
8 & 1-methyl-4-ethylbenzene \\
9 & 1,3,5-trimethylbenzene \\
10 & 1-methyl-2-ethylbenzene \\
11 & $1,2,4-$ trimethylbenzene \\
12 & 1,2,3-trimethylbenzene \\
13 & 1-methyl-3-isopropylbenzene \\
14 & 1-methyl-4-isopropylbenzene \\
15 & 1-methyl-2-isopropylbenzene \\
16 & 1,3-diethylbenzene \\
17 & 1-methyl-3-propylbenzene \\
18 & 1,4-diethylbenzene \\
19 & 1-methyl-4-propylbenzene \\
20 & $n$-butylbenzene \\
21 & 1,3-dimethyl-5-ethylbenzene \\
22 & 1,2-diethylbenzene \\
23 & 1-methyl-2-propylbenzene \\
24 & 1,4-dimethyl-2-ethylbenzene \\
25 & 1,3-dimethyl-4-ethylbenzene \\
26 & 1,2-dimethyl-4-ethylbenzene \\
27 & 1,3-dimethyl-2-ethylbenzene \\
28 & 1,2,3,4-tetramethylbenzene \\
\hline &
\end{tabular}

Note: Numbers refer to peaks identified in Figures 7 and 8.

many algaenans (Gatellier et al., 1993; Derenne et al., 1989; Gelin et al., 1996). The isoprenoid ketone 6,10,14-trimethyl-2-pentadecanone may originate from a similar isoprenoid algaenan to that mentioned above (see Behar et al., 1995).

Alkylbenzenes in kerogens can have many precursors (e.g., Hartgers et al., 1994a). One group of precursors is formed by the aromatic carotenoids, biosynthesized by photosynthetic green sulfur bacteria, and incorporated into the kerogen matrix, which, upon pyrolysis, yields high amounts of, for example, 1,2,3,4-tetramethylbenzene (TMB; Hartgers et al., 1995). In addition to the aromatic carotenoids, an alternative source has been suggested recently by Hoefs et al. (1995). The presence of TMB in pyrolysates of stable residues of several marine algae indicates that TMB may also have an algal origin. Koopmans et al. (1996) have shown that it is possible to form $\beta$-isorenieratane from $\beta$-carotene in laboratory simulations and, via $\delta^{13} \mathrm{C}$ values of $\beta$-carotane and $\beta$-isorenieratane, the possible genetic relationship of these compounds in nature. It seems therefore likely that TMB can be formed, upon pyrolysis, from macromolecularly bound $\beta$-isorenieratene, which is diagenetically derived from the ubiquitous carotenoid $\beta$-carotene. This latter algal source seems more likely since green sulfur bacteria need both light and hydrogen sulfide, and it seems unlikely that photic-zone euxinia existed in the northwest Atlantic in the recent past. The so-called "linear" alkylbenzenes are thought to be formed by cyclization and aromatization reactions of linear, functionalized precursors (Derenne et al., 1990b; Sinninghe Damsté et al., 1991; Hartgers et al., 1994a), leading to aromatic moieties with linear carbon skeletons.

Incorporation of reduced inorganic sulfur species into labile biochemicals during the early stages of diagenesis can lead to the formation of mono- and polysulfide and alkylthiophene moieties in kerogens (Sinninghe Damsté, et al., 1989a, 1989b). It has been suggested that alkylated thiophenes present in pyrolysates of macromolecular sedimentary organic matter are formed, upon pyrolysis, from existing thiophene moieties in kerogens (Sinninghe Damsté, et al., 1989a, 1989b; Kohnen et al., 1991). Recently, however, it has been proposed that it is more likely that alkylated thiophenes are formed from multiple (poly)sulfide-bound, short $\left(\mathrm{C}_{5}-\mathrm{C}_{7}\right)$, alkyl skeletons, probably formed by incorporation through sulfurization of carbohydrates in kerogens (Van Kaam-Peters et al., in press). This hypothesis has been tested by the artificial sulfurization of an alga (Phaeocystis) that contains large amounts of carbohydrates. Pyrolysis of the residue of this modified alga resulted in a series of alkylated thiophenes similar to the thiophenes found in the MAP turbidites (M. Kok et al., unpub. data).

Phenols are often found in the pyrolysates of kerogens. The origin of these phenols can be manifold. For example, proteins (i.e., tyrosine moieties; Tsuge and Matsubara, 1985), seed coats of higher plants (Van Bergen et al., 1993, 1994), and modified lignin (Saiz-Jimenez and De Leeuw, 1986; Collinson et al., 1994; Hatcher and Spiker, 1988). The occurrence of polyphenolic compounds in marine macroalgae has also been described (Ragan, 1976; Ragan and Craigie, 1978; Van Alstyne, 1988; J.D.H. van Heemst et al., unpubl. data). Excluding a possible marine algal source for the phenols, and assuming that they are derived primarily from modified lignins, these compounds are the only clue for a contribution of terrestrial organic matter to the OM in the turbidites. It seems, therefore, that the contribution of terrestrial organic matter to the total $\mathrm{OM}$ is relatively small.

\section{Postdepositional Oxidation Effect on the Bulk Composition of the OM}

Three major compound classes in the pyrolysates show the largest change across the oxidation fronts. The $n$-alkanes and $n$-alk-1-enes show the largest relative increase in abundance, whereas the isoprenoid alkanes and alkenes and the alkylthiophenes show the largest relative drop (Fig. 3; Table 7). The increase in relative abundance of the $n$-alkanes and $n$-alk-1-enes can be explained from their biological origin (i.e., $n$-alkyl algaenans). These macromolecules are comparatively well capable of resisting the bacterial and chemical degradation that takes place during the oxidation of organic matter in the turbidites, and they are therefore relatively enriched in the oxidized turbidite samples (Fig. 3; Table 7). Additional evidence for this relative enrichment can be found in the change of the alkylbenzene distribution pattern (Fig. 7). The pyrolysates of the oxidized turbidite samples are relatively enriched in linear alkylbenzenes, such as 1-methyl2 - $n$-alkylbenzene and $n$-propylbenzene, which are formed by cyclization and aromatization of linear functionalized precursors (Table 3).

In contrast, the large decrease in relative abundance of the isoprenoid alkanes and alkenes in the kerogen pyrolysates of oxidized MAP turbidites (Fig. 3; Table 7) suggests that the preservation potential of these isoprenoid moieties in the kerogens, possibly derived from isoprenoid algaenans, is substantially lower than that of the $n$ alkyl moieties. This is confirmed by the large co-occurring drop in relative abundance of 6,10,14-trimethyl-2-pentadecanone, which also may have an isoprenoid algaenan origin. It seems, therefore, that the $n$-alkyl algaenans have a higher preservation potential than the isoprenoid algaenans. The enhanced degradation of the proposed isoprenoid algaenan component in the kerogen is remarkable. Biodegradation of oils, although not directly comparable to oxic degradation of macromolecular matter, typically results in an increased abundance of the isoprenoid alkanes and a decrease in abundance of the $n$ alkanes (Connan, 1984). The reason for this apparent contradiction is not yet clear.

The large drop in relative abundance of the alkylthiophenes in the pyrolysates of oxidized turbidite samples suggests that alkylated thiophenic moieties in the kerogens are less resistant to postdepositional oxidation than, for example, the alkylated benzenes, which seems unlikely on chemical grounds. Both compound classes are aromatic and, therefore, chemically rather stable. However, alternative precursors of alkylthiophenes in pyrolysates of kerogens are multiple (poly)sulfide-bound carbohydrate skeletons (Van Kaam-Peters et al., in press), which would, via oxidation of the sulfur atom, be much less 

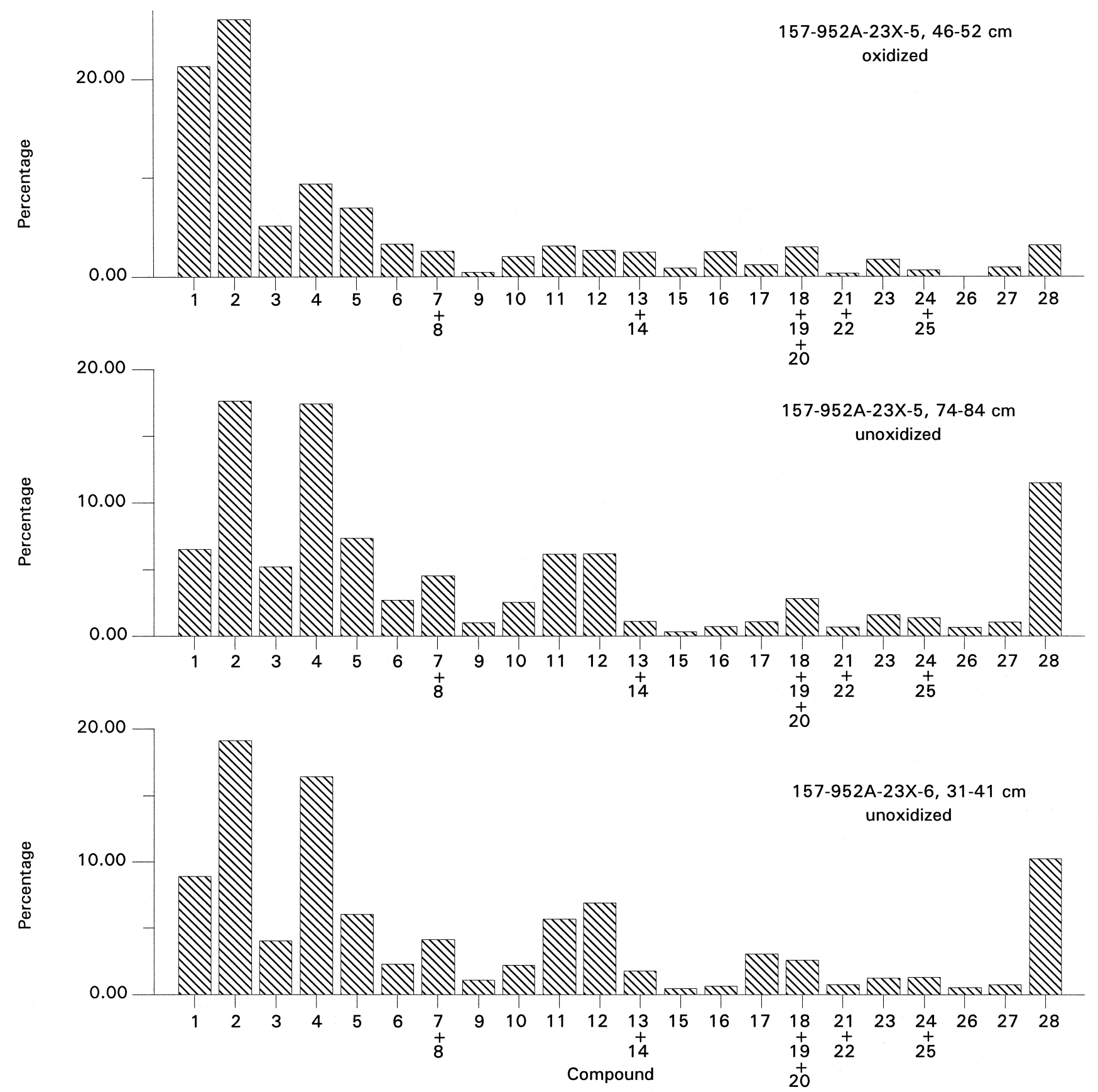

Figure 8. Bar plots showing the internal distributions of the $\mathrm{C}_{0}-\mathrm{C}_{4}$ alkylated benzenes of turbidite 157-952A-23X kerogen samples. The numbers on the $\mathrm{x}$-axis refer to compounds listed in Table 4.

resistive against oxidation. Therefore, the decrease in alkylated thiophenes in the pyrolysates may indicate that they indeed stem from mono- and polysulfidic-bound carbohydrates and not from thiophenic moieties present as such in the kerogens. The $\delta^{13} \mathrm{C}_{\mathrm{TOC}}$ values of the oxidized samples are $0.65 \%$ o to $2.2 \%$ lighter than the corresponding unoxidized samples (Table 2). In addition to the preferential preservation - relative to TOC —of plant-wax $n$-alkanes, such an isotopic shift has been used by Prahl et al. (1997) to calculate the increased contribution of terrestrial organic matter to the oxidized MAP f-turbidite. They proposed a binary mixing model between ${ }^{13} \mathrm{C}$ depleted terrestrial organic matter and ${ }^{13} \mathrm{C}$-enriched marine $\mathrm{OM}$, whereby preferential preservation of terrestrial OM during postdepositional oxidation could explain the observed isotopic shifts in the
MAP f-turbidite OM. There is, however, no evidence from our pyrolysis data for an enrichment of terrestrial OM. The alkylphenols, for example, which may also have an marine algal source, form the only clue for a contribution of terrestrial OM, but do not increase in the pyrolysate of the oxidized turbidites (Fig. 3). To explain the observed change in carbon isotopic composition across the oxidation front it is not, however, required to assume a relative enrichment of terrestrial OM. Oxidation and removal of the sulfurized carbohydrates from the kerogen may also explain the observed decrease of the $\delta^{13} \mathrm{C}$ value of the TOC of the oxidized turbidite samples. It has been found in pyrolysates of the Kimmeridge Clay Formation sediments that the $n$ alkanes have a $\delta^{13} \mathrm{C}$ value of $\sim-30 \%$, whereas the $\delta^{13} \mathrm{C}$ value of the thiophenes is $\sim-21 \%$ o (Van Kaam-Peters et al., in press). Assuming 


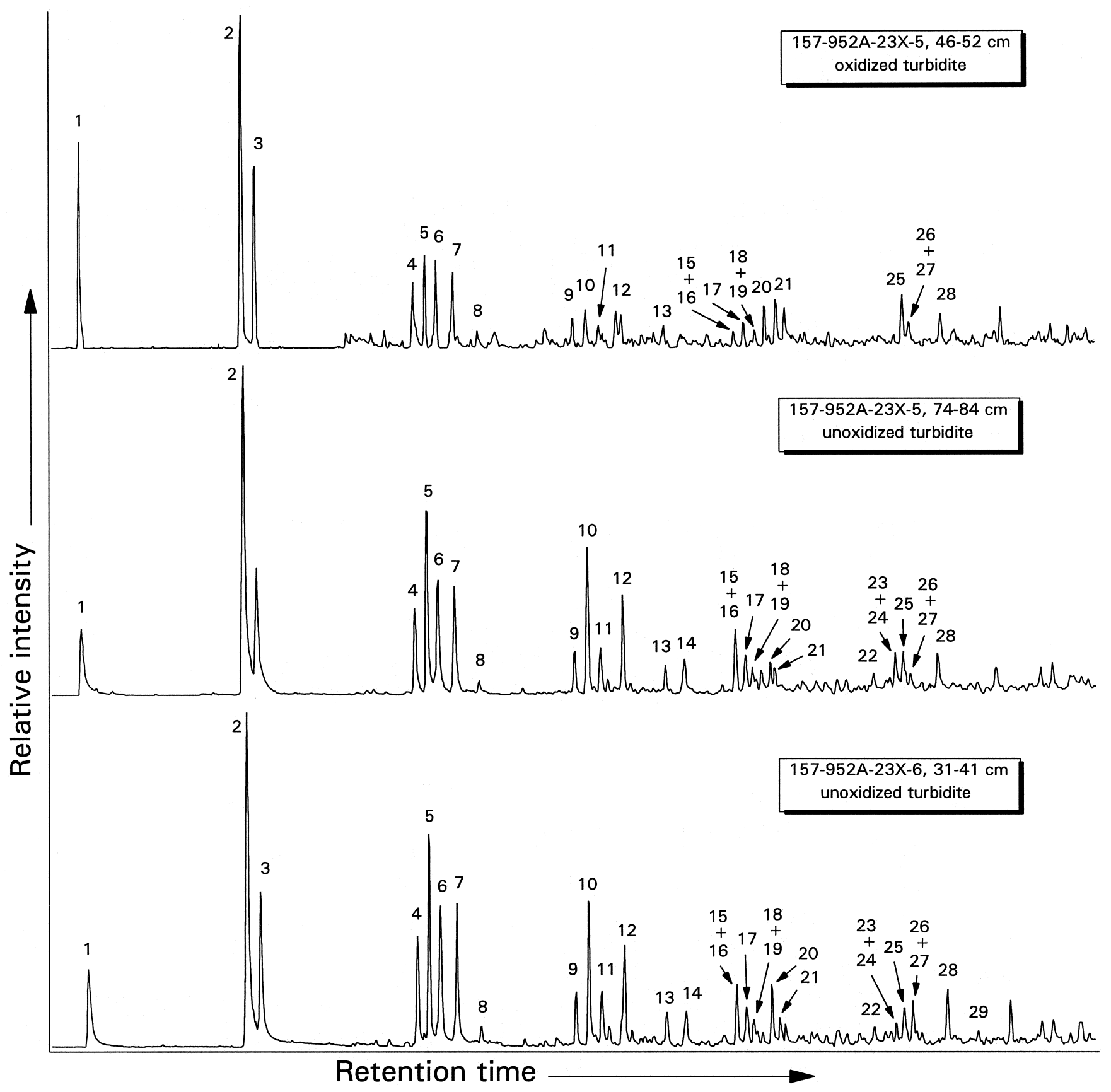

Figure 9. Summed mass chromatograms $(m / z, 84+97+98+111+112+125+126+139+140+153+154)$ of flash pyrolysates of turbidite $157-952 \mathrm{~A}-23 \mathrm{X}$, illustrating the internal distributions of the $\mathrm{C}_{0}-\mathrm{C}_{5}$ alkylated thiophenes. The numbers refer to compounds listed in Table 5 .

similar isotopic signatures in the MAP kerogen components, removal of the isotopically heavy sulfur-bound carbohydrates, as represented in the pyrolysate by the thiophenes, will shift the $\delta^{13} \mathrm{C}$ value of the TOC toward lighter values.

Cowie et al. (1995) argued that degradation of sedimentary organic matter in the f-turbidite was largely nonselective for the analytes measured (TOC, total nitrogen [TN], lignin, carbohydrates, and amino acids). Prahl et al. (1997) also concluded this, although $\delta^{13} \mathrm{C}$ values and concentration of biomarkers indicated more selective degradation of the OM. However, our data show that the kerogen fraction in the MAP turbidites was degraded selectively. Since kerogen represents by far (>95\% by weight; Durand and Nicaise, 1980) the largest part of the total organic matter, we conclude that degradation of
OM in MAP turbidites is significantly more selective than previously indicated (Cowie et al., 1995; Prahl et al., 1997).

\section{Additional Postdepositional Oxidation Effects}

The $n$-alkane and $n$-alk-1-ene distribution patterns of the pyrolysates of the oxidized turbidites show differences in the maximum chain length among the four turbidites. This may be caused by mixtures of different algaenans with different degradabilities. The most severely degraded turbidites, like turbidites $3 \mathrm{x}$ and $23 \mathrm{x}$, show internal distributions of the $n$-alkanes and $n$-alk-1-enes that extend to $\mathrm{C}_{32}$, whereas turbidites, such as $18 \mathrm{x}$ and $9 \mathrm{~h}$, which are relatively less severely degraded, do not show their $n$-alkane and $n$-alkene distribu- 
Table 5. Alkylthiophenes identified in kerogen pyrolysates.

\begin{tabular}{ll}
\hline Peak & \multicolumn{1}{c}{ Compound } \\
\hline 1 & Thiophene \\
2 & 2-methylthiophene \\
3 & 3-methylthiophene \\
4 & 2-ethylthiophene \\
5 & 2,5-dimethylthiophene \\
6 & 2,4-dimethylthiophene \\
7 & 2,3-dimethylthiophene \\
8 & 3,4-dimethylthiophene \\
9 & 2-propylthiophene \\
10 & 2-ethyl-5-methylthiophene \\
11 & 2-ethyl-4-methylthiophene \\
12 & 2,3,5-trimethylthiophene \\
13 & 2,3,4-trimethylthiophene \\
14 & Isopropylmethylthiophene \\
15 & 2-methyl-5-propylthiophene \\
16 & 2,5-diethylthiophene \\
17 & 2-butylthiophene \\
18 & 2-ethyl-3,5-dimethylthiophene \\
19 & Ethyldimethylthiophene \\
20 & 5-ethyl-2,3-dimethylthiophene \\
21 & ethyldimethylthiophene \\
22 & C4:1 thiophene \\
23 & 3,5-dimethyl-2-propylthiophene \\
24 & C5 - thiophene \\
25 & 2-butyl-5-methylthiophene \\
26 & 2-pentylthiophene \\
27 & 2,3-dimethyl-5-propylthiophene \\
28 & C5 - thiophene \\
29 & C5 - thiophene \\
& \\
\hline &
\end{tabular}

Note: Numbers refer to peaks identified in Figure 9.

tions extending to $\mathrm{C}_{32}$. The algaenans that yield the longer chain $n$ alkanes and $n$-alk-1-enes are probably present at levels that are comparatively negligible in the unoxidized samples but, because of stability, become more important in the oxidized samples. Therefore, the most severely oxidized turbidites exhibit this phenomenon most clearly.

The increase in unsaturation of the $n$-alkanes and $n$-alk-1-enes distribution pattern, expressed in the USI (Table 3), is most likely caused by a hydrogen deficiency in the kerogens of the oxidized turbidites. McArthur et al. (1992) also reported this for the MAP a-and e-turbidite, where they found a decrease across the oxidation front of the hydrogen index (HI) by $25 \%$ and $50 \%$, respectively. This leads to a higher production of $n$-alk-1-enes instead of $n$-alkanes upon pyrolysis of the kerogens. A hydrogen-deficient kerogen may originate from enhanced preservation of more highly cross-linked algaenans or, alternatively, from an increase in cross-linking in the algaenans caused by the oxidative process. The first explanation seems more likely in view of the fact that the algaenan component of the organic matter is oxidized as well.

Another striking result is the pristene precursors' differing resistance to oxidation. The precursors of prist-1-ene, probably bound tocopherols (Goossens et al., 1984), are degraded more extensively than the unknown prist-2-ene precursor, as is expressed in the prist1 -ene/(prist-1-ene + prist-2-ene) ratio (Table 3). These results suggest that the tocopherol moieties in the kerogens are more susceptible to oxidation by molecular oxygen than are the precursors for prist-2ene.

The alkylbenzene distribution patterns of the pyrolysates of the oxidized turbidite samples are severely depleted in TMB (Fig. 7). This leads to the conclusion that the alternative precursors for TMB (Hoefs et al., 1995; Koopmans et al., 1996) have a lower preservation potential under oxidizing conditions than the precursors for the rest of the alkylbenzene isomers.

The degree of alkylation of the alkylbenzenes, alkylnaphthalenes, alkylphenols, and alkylthiophenes is expressed by the alkylation indices in Table 3. All of these compound classes show an increase of the less alkylated $\left(\mathrm{C}_{0}-\mathrm{C}_{1}\right)$ isomers. Only the alkylthiophenes show a less pronounced change in degree of alkylation. For the alkylphenols it has been found (Van Bergen et al., 1994) that the oxidized outer seed coats of water plants yielded more $\mathrm{C}_{0}-\mathrm{C}_{1}$ alkylated phenols than the unoxidized outer seed coats. If this holds for all the compound classes, we can link this alkylation phenomenon directly to the effect of oxidation by molecular oxygen on the sedimentary organic matter of the MAP turbidites.

\section{CONCLUSIONS}

1. The original organic matter in the turbidites is very homogeneous in composition. Even on a molecular level, the OM is remarkably similar, as is represented by the identical relative abundance of the compound classes present in the pyrolysates and the virtually identical internal distributions of these compound classes in the two unoxidized sample pairs.

2. The chemical composition of the kerogens in the oxidized turbidites is significantly different from that in the unoxidized intervals. The relative abundance of the isoprenoid alkanes and alkenes and the alkylthiophenes show the largest drop, whereas the $n$-alkanes and $n$-alk-1-enes show the largest increase in the pyrolysates of the oxidized samples. The relative abundances of the other analyzed compound classes remain fairly constant. However, the decrease in TOC, ranging from $72 \%$ to $87 \%$ for the four turbidites studied, indicates that the absolute abundance of all analyzed compound classes is much lower in the oxidized samples. The relative increase in the linear algaenan component leads to an increase in the aliphatic character of the pyrolysate of the macromolecular OM after oxidation. This is evidence for the high relative preservation potential of highly aliphatic biomacromolecules under oxidizing conditions.

3. Evidence was found for a possible isoprenoid algaenan in OM of the MAP turbidites. The origin of the postulated marine isoprenoid algaenan is as yet unknown. It is clear, however, that its preservation potential is substantially lower than that of the $n$-alkyl algaenan. Furthermore, the preservation potential of the tocopherol precursor of prist-1-ene is much lower than that of the unknown precursor of prist-2-ene.

4. The alkylbenzenes show preferential preservation of the "linear" alkylbenzenes, providing evidence for the existence of linear functionalized precursors in the kerogens. The precursors of TMB in the kerogens show evidence for preferential degradation. Considering the (paleo)depositional environment, these precursors are not aromatic carotenoids and have to be found in an alternative source.

5. The alkylthiophenes show a large relative abundance drop in the oxidized samples. This drop is not caused by degradation of thiophenic moieties in the kerogens as such, but more likely by the degradation of relatively labile precursors such as mono- and polysulfidic-bound carbohydrate carbon skeletons. Removal of such carbohydrate skeletons, which are likely to be isotopically heavy, may also explain the drop in $\delta^{13} \mathrm{C}$ of the TOC. In agreement with the lack of pyrolytic evidence for a large terrestrial contribution to the kerogens, selective enrichment of isotopically light terrestrial OM is not required to explain the $\delta^{13} \mathrm{C}$ excursion in the oxidized part of the turbidite.

\section{ACKNOWLEDGMENTS}

The authors wish to thank Mrs. H. De Waard, Mr. R. Alink, Mrs. M. Dekker, and Mr. W. Pool for technical assistance. We also would like to thank Dr. G. Cowie for his thorough review and constructive comments. This work was supported by a PIONIER grant to JSSD from NWO. NIOZ Contribution No. 3139. This is NSG Paper no. 960605. 

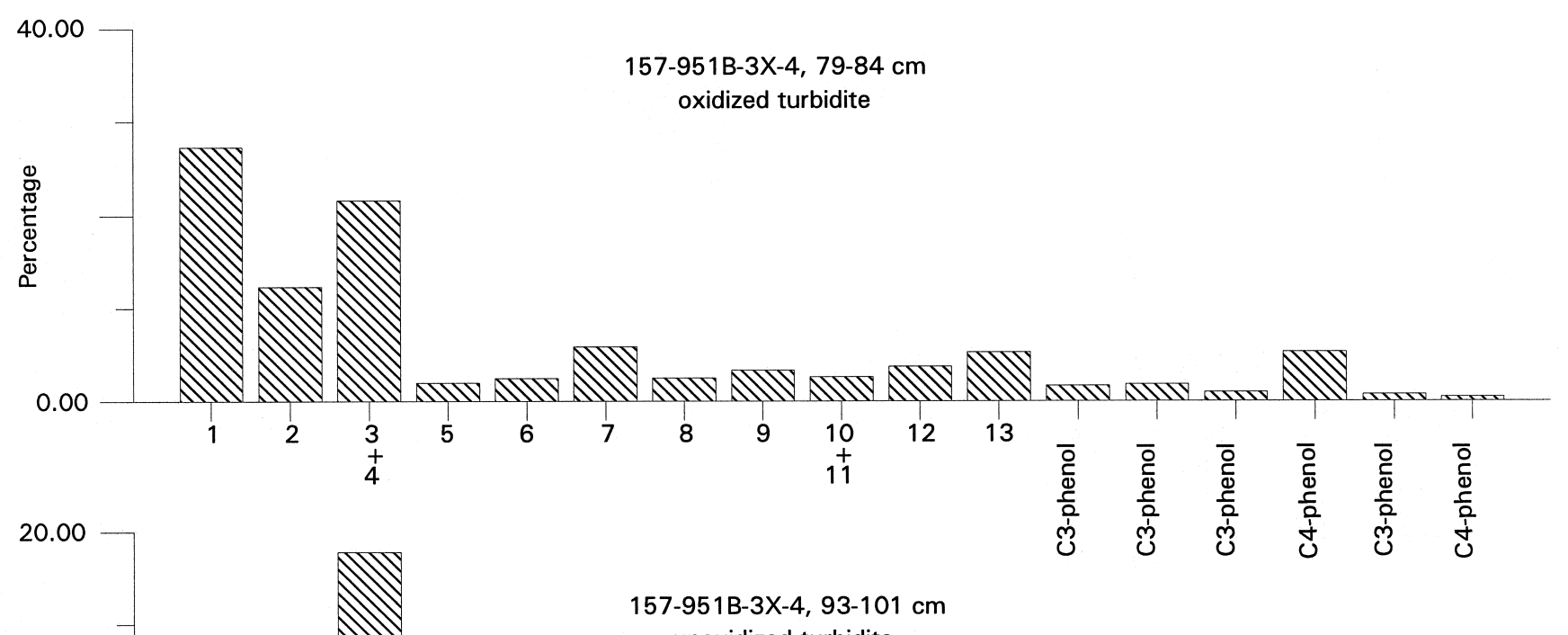

unoxidized turbidite
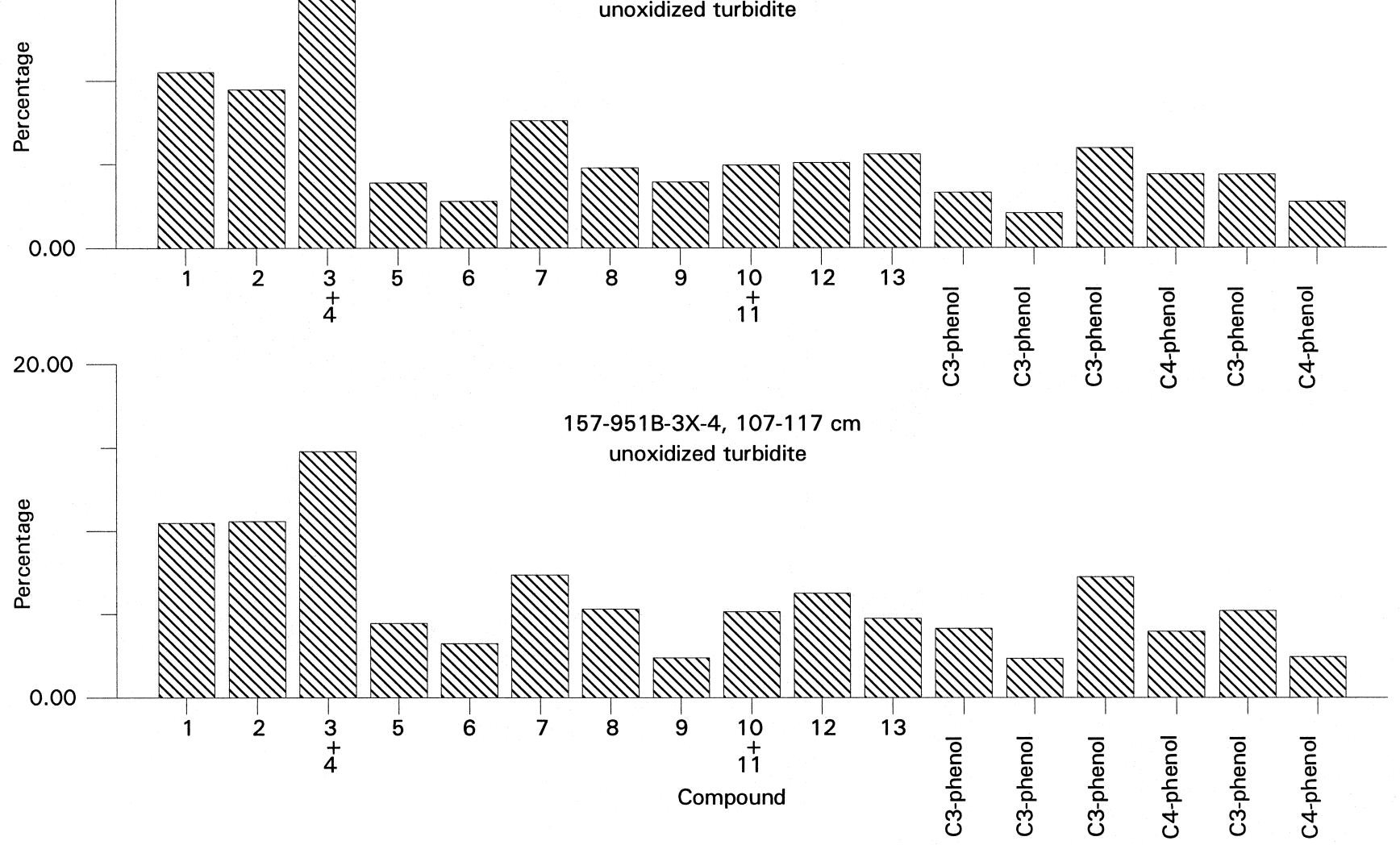

Figure 10. Bar plots showing the internal distributions of the $\mathrm{C}_{0}-\mathrm{C}_{4}$ alkylated phenols $(\mathrm{m} / \mathrm{z} 94+107+108+121+122+135+136)$ of turbidite $157-951 \mathrm{~B}-3 \mathrm{X}$ kerogen samples. The numbers on the $\mathrm{x}$-axis refer to compounds listed in Table 6 .

\section{REFERENCES}

Behar, F., Derenne, S., and Largeau, C., 1995. Closed pyrolyses of the isoprenoid algaenan of Botryococcus braunii, $L$ race: geochemical implications for derived kerogens. Geochim. Cosmochim. Acta, 59:2983-2997.

Calvert, S.E., Bustin, R.M., and Pedersen, T.F., 1992. Lack of evidence for enhanced preservation of sedimentary organic matter in the oxygen minimum of the Gulf of California. Geology, 20:757-760.

Calvert, S.E., and Pedersen, T.F., 1992. Organic carbon accumulation and preservation in marine sediments: how important is anoxia? In Whelan, J.K., and Farrington, J.W. (Eds.), Organic Matter: Productivity, Асcumulation and Preservation in Recent and Ancient Sediments: New York (Columbia Univ. Press), 231-263.
Canfield, D.E., 1989. Sulfate reduction and oxic respiration in marine sediments: implications for organic carbon preservation in euxinic environments. Deep-Sea Res. Part A, 36:121-138.

1993. Organic matter oxidation in marine sediments. In Wollast, R., Chou, L., and Mackenzie, F. (Eds.), Interactions of $C, N$, $P$, and S Biogeochemical Cycles. NATO Adv. Res. Workshop, Berlin, 333-363.

Collinson, M.E., Van Bergen, P.F., Scott, A.C., and De Leeuw, J.W., 1994. The oil-generating potential of plants from coal and coal-bearing strata through time: a review with new evidence from Carboniferous plants. In Scott, A.C., and Fleet, A.J. (Eds.), Coal and Coal-bearing Strata as Oilprone Source Rocks-Geol. Soc. Spec. Publ. London, 77:31-70.

Connan, J., 1984. Biodegradation of crude oils in reservoirs. In Brooks, J., and Welte, D. (Eds.), Advances in Petroleum Geochemistry: London (Academic Press), 1:299-335. 
Cowie, G.L., Hedges, J.I., Prahl, F.G., and de Lange, G.J., 1995. Elemental and major biochemical changes across an oxidation front in a relict turbidite: an oxygen effect. Geochim. Cosmochim. Acta, 59:33-46.

De Lange, G.J., Jarvis, I., and Kuijpers, A., 1987. Geochemical characteristics and provenance of late Quaternary sediments from the Madeira Abyssal Plain, North Atlantic. In Weaver, P.P.E., and Thomson, J. (Eds.), Geology and Geochemistry of Abyssal Plains. Geol. Soc. Spec. Publ. London, 31:147-165.

De Leeuw, J.W., and Largeau, C., 1993. A review of macromolecular organic compounds that comprise living organisms and their role in kerogen, coal and petroleum formation. In Engel, M.H., and Macko, S.A. (Eds.), Organic Geochemistry, Principles and Applications: New York (Plenum), 23-72.

Demaison, G.J., and Moore, G.T., 1980. Anoxic environments and oil source bed genesis. AAPG Bull., 64:1179-1209.

Derenne, S., Largeau, C., Berkaloff, C., Rousseau, B., Wilhelm, C., and Hatcher, P.G., 1992. Non-hydrolyzable macromolecular constituents from outer walls of Chlorella fusca and Nanochlorum eucaryotum. Phytochemistry, 31:1923-1929.

Derenne, S., Largeau, C., Casadevall, E., and Berkaloff, C., 1989. Occurrence of a resistant biopolymer in the $\mathrm{L}$ race of Botryococcus braunii. Phytochemistry, 28:1137-1142.

Derenne, S., Largeau, C., Casadevall, E., and Sellier, N., 1990a. Direct relationship between the resistant biopolymer and the tetraterpenic hydrocarbon in the lycopadiene-race of Botryococcus braunii. Phytochemistry, 29:2187-2192.

Derenne, S., Largeau, C., Casadevall, E., Sinninghe Damsté, J.S., Tegelaar, E.W., and De Leeuw, J.W., 1990b. Characterization of Estonian Kukersite by spectroscopy and pyrolysis: evidence for abundant alkyl phenolic moieties in an Ordovician marine, type II/I kerogen. Org. Geochem., 16:873888

Durand, B., and Nicaise, G., 1980. Procedures for kerogen isolation. In Durand, B. (Ed.), Kerogen Insoluble Organic Matter From Sedimentary Rocks: Paris (Editions Technip), 35-53.

Flügge, A., 1996. Diagenetic degradation of long-chain alkenones: implications for $\mathrm{U}^{\mathrm{k}}{ }_{37}$ paleo-thermometry. J. Conf. Abs., 1:171.

Gatellier, J.-P.L.A., De Leeuw, J.W., Sinninghe Damsté, J.S., Derenne S., Largeau, C., and Metzger, P., 1993. Very early diagenesis of a resistant cell wall biomacromolecule of the green alga Botryococcus braunii (Race A) as revealed by spectroscopic and pyrolysis investigations of a Coorongite. Geochim. Cosmochim. Acta, 57:2053-2068.

Gelin, F., Boogers, I., Noordeloos, A.A.M., Hatcher, P.G., Sinninghe Damsté, J.S., and De Leeuw, J.W., 1996. Novel, resistant microalgal polyethers: an important sink of organic carbon in the marine environments? Geochim. Cosmochim. Acta, 60:1275-1280.

Gelin, F., Gatellier, J.-P.L.A., Sinninghe Damsté, J.S., Derenne, S., Largeau, C., Metzger, P., and De Leeuw, J.W., 1993. Mechanisms of flash pyrolysis of ether lipids isolated form the green microalga Botryococcus braunii. J. Anal. Appl. Pyrolysis, 27:155-168.

Gelin, F., Sinninghe Damsté, J.S., Derenne, S., Largeau, C., Metzger, P., and De Leeuw, J.W., 1994. Scope and limitations of flash pyrolysis-gas chromatography/mass spectrometry as revealed by the thermal behavior of high-molecular weight lipids derived from the green microalga Botryococcus braunii. J. Anal. Appl. Pyrolysis, 28:183-204.

Goossens, H., De Leeuw, J.W., Schenk, P.A., and Brassell, S.C., 1984. Tocopherols as likely precursors of pristane in ancient sediment and crude oils. Nature, 312:440-442.

Goth, K., De Leeuw, J.W., Püttman, W., and Tegelaar, E.W., 1988. Origin of Messel Oil Shale kerogen. Nature, 336:759-761.

Hartgers, W.A., Sinninghe Damsté, J.S., and De Leeuw, J.W., 1992. Identification of $\mathrm{C}_{2}-\mathrm{C}_{4}$ alkylated benzenes in flash pyrolysates of kerogens, coals and asphaltenes. J. Chromatogr., 606:211-220.

Hartgers, W.A., Sinninghe Damsté, J.S., and De Leeuw, J.W., 1994a. Geochemical significance of alkylbenzene distributions in flash pyrolysates of kerogens, coals and asphaltenes. Geochim. Cosmochim. Acta, 58:1759-1775.

Hartgers, W.A., Sinninghe Damsté, J.S., De Leeuw, J.W., Ling, Y. and Dyrkacz, G.R., 1994b. Molecular characterization of two carboniferous coals and their constituting maceral fractions. Energy Fuels, 8:10551067.

Hartgers, W.A., Sinninghe Damsté, J.S., Requejo, A.G., Allan, J., Hayes, J.M., Ling, Y., Xie, T.-M., Primack, J., and De Leeuw, J.W., 1995. A molecular and carbon isotopic study towards the origin and diagenetic fate of diaromatic carotenoids. Org. Geochem., 22:703-726.
Hatcher, P.G., and Spiker, E.C., 1988. Selective degradation of plant biomolecules. In Frimmel, F.H., and Christman, R.F. (Eds.), Humic Substances and Their Role in the Environments: New York (Wiley), 59-74.

Henrichs, S.M., and Reeburgh, W.S., 1987. Anaerobic mineralization of marine sediment organic matter: rates and the role of anaerobic processes in the oceanic carbon economy. J. Geomicrobiol., 5:191-237.

Hoefs, M.J.L., Van Heemst, J.D.H., Gelin, F., Koopmans, M.P., Van KaamPeters, H.M.E., Schouten, S., De Leeuw, J.W., and Sinninghe Damsté, J.S., 1995. Alternative biological sources for 1,2,3,4-tetramethylbenzene in flash pyrolysates of kerogens. Org. Geochem., 23:975-980.

Ioppolo, M., Alexander, R., and Kagi, R.I., 1992. Identification and analysis of $\mathrm{C}_{0}-\mathrm{C}_{3}$ phenols in some Australian crude oils. Org. Geochem., 18:603609.

Keil, R.G., Hu, F.S., Tsamakis, E.C., and Hedges, J.I., 1994. Pollen in marine sediments as an indicator of oxidation of organic matter. Nature, 369:639-641

Kohnen, M.E.L., Sinninghe Damsté, J.S., Ten Haven, H.L., Kock-van Dalen, A.C., Schouten, S., and De Leeuw, J.W., 1991. Identification and geochemical significance of cyclic di- or trisulfides with linear and acyclic isoprenoid carbon skeletons in immature sediments. Geochim. Cosmochim. Acta, 55:3685-3695.

Koopmans, M.P., Schouten, S., Kohnen, M.E.L., and Sinninghe Damsté, J.S., 1996. Restricted utility of aryl isoprenoids as indicators for photic zone anoxia. Geochim. Cosmochim. Acta, 60:4873-4876.

Largeau, C., Casadevall, E., Kadouri, A., and Metzger, P., 1984. Formation of Botryococcus-derived kerogens: comparative study of immature torbanites and of the extant alga Botryococcus braunii. In Schenck, P.A., De Leeuw, J.W., and Lijmbach G.M.M. (Eds.), Advances in Organic Geochemistry 1983. Org. Geochem., 6:327-332.

McArthur, J.M., Tyson, R.V., Thomson, J., and Mattey, D., 1992. Early diagenesis of marine organic matter: alteration of the carbon isotopic composition. Mar. Geol., 105:51-61.

Morris, R.J., 1987. Turbidite flows as a source of organic matter in deep water marine deposits: evidence from Quaternary sediments on the Madeira Abyssal Plain. Mem. Soc. Geol. Fr., 151:43-53.

Paropkari, A.L., Babu, C.P., and Mascarenhas, A., 1992. A critical evaluation of depositional parameters controlling the variability of organic carbon in Arabian Sea sediments. Mar. Geol., 107:213-226.

Pedersen, T.F., and Calvert, S.E., 1990. Anoxia vs. productivity: what controls the formation of organic-carbon-rich sediments and sedimentary rocks? AAPG Bull., 74:454-466.

Prahl, F.G., de Lange, G.J., Lyle, M., and Sparrow, M.A., 1989. Post-depositional stability of long-chain alkenones under contrasting redox conditions. Nature, 341:434-437.

Prahl, F.G., de Lange, G.J., Scholten, S., and Cowie, G.L., 1997. A case for postdepositional aerobic degradation of terrestrial organic matter in turbidite deposits from the Madeira Abyssal Plain. Org. Geochem., 27:141152.

Pratt, L.M., 1984. Influence of paleoenvironmental factors on preservation of organic matter in the middle Cretaceous Greenhorn Formation, Pueblo Co. AAPG Bull., 68:1146-1159.

Ragan, M.A., 1976. Physodes and phenolic compounds of brown algae: composition and significance of physodes in vivo. Bot. Mar., 19:145-154.

Ragan, M.A., and Craigie, J.S., 1978. Phenolic compounds in brown and red algae. In Hellebust, J.A., and Craigie, J.S. (Eds.), Handbook of Phycological Methods (Vol. 2): Cambridge (Cambridge Univ. Press).

Regtop, R.A., Crisp, P.T., Ellis, J., and Fooks, C.J.R., 1986. 1-Pristene as a precursor for 2-pristene in pyrolysates of oil shale from Condor, Australia. Org. Geochem., 9:233-236.

Saiz-Jimenez, C., and De Leeuw, J.W., 1986. Lignin pyrolysis products: their structures and their significance as biomarkers. Org. Geochem., 6:295304.

Sinninghe Damsté, J.S., Eglinton, T.I., De Leeuw, J.W., and Schenck, P.A., 1989a. Organic sulfur in macromolecular sedimentary organic matter. I: Structure and origin of sulfur-containing moieties in kerogen, asphaltenes and coal as revealed by flash pyrolysis. Geochim. Cosmochim. Acta, 53:873-889.

Sinninghe Damsté, J.S., Kock-van Dalen, A.C., Albrecht, P.A., and De Leeuw, J.W., 1991. Identification of long chain 1,2-di- $n$-alkylbenzenes in Amposta crude oil from the Tarragona Basin, Spanish Mediterranean: implications for the origin and fate of alkylbenzenes. Geochim. Cosmochim. Acta, 55:3677-3683

Sinninghe Damsté, J.S., Kock-van Dalen, A.C., De Leeuw, J.W., and Schenck, P.A., 1988. Identification of homologous series of alkylated 
thiophenes, thiolanes, thianes and benzothiophenes in pyrolysates of sulphur-rich kerogens. J. Chromatogr., 435:435-452.

Sinninghe Damsté, J.S., Rijpstra, W.I.C., Kock-van Dalen, A.C., De Leeuw, J.W., and Schenck, P.A., 1989b. Quenching of labile functionalized lipids by inorganic sulphur species: evidence for the formation of sedimentary organic sulfur compounds at the early stages of diagenesis. Geochim. Cosmochim. Acta, 53:1343-1355.

Tsuge, S., and Matsubara, H., 1985. High-resolution pyrolysis-gas chromatography of proteins and related materials. J. Anal. Appl. Pyrolysis, 8:4964.

Van Alstyne, K.L., 1988. Herbivore grazing increases polyphenolic defenses in the intertidal brown alga Fucus distichus. Ecology, 69:655-663.

Van Bergen, P.F., Collinson, M.E., and De Leeuw, J.W., 1993. Chemical composition and ultrastructure of fossil and extant salvinialean microspore massulae and megaspores. Grana (Suppl. 1), 18-30.

Van Bergen, P.F., Goñi, M., Collinson, M.E., Barrie, P.J., Sinninghe Damsté, J.S., and De Leeuw, J.W., 1994. Chemical and microscopic characteriza- tion of outer seed coats of fossil and extant water plants. Geochim. Cosmochim. Acta, 58:3823-3844.

Van Kaam-Peters, H.M.E., Schouten, S., De Leeuw, J.W., Sinninghe Damsté, J.S., in press. Palaeoenvironmental controls on the preservation of organic matter in the Kimmeridge Clay Formation as revealed by biomarkers, molecular stable isotope analysis and pyrolysis. Geochim. Cosmochim Acta.

Weaver, P.P.E., and Kuijpers, A., 1983. Climatic control of turbidite deposition on the Madeira Abyssal Plain. Nature, 306:360-363.

Date of initial receipt: 3 July 1996

Date of acceptance: 24 January 1997

Ms 157SR-140

Table 6. Alkylphenols identified in kerogen pyrolysates.

\begin{tabular}{ll}
\hline Peak & \multicolumn{1}{c}{ Compound } \\
\hline 1 & Phenol \\
2 & 2-methylphenol \\
3 & 4-methylphenol \\
4 & 3-methylphenol \\
5 & 2,6-dimethylphenol \\
6 & 2-ethylphenol \\
7 & 2,4-dimethylphenol \\
8 & 2,5-dimethylphenol \\
9 & 4-ethylphenol \\
10 & 3-ethylphenol \\
11 & 3,5-dimethylphenol \\
12 & 2,3-dimethylphenol \\
13 & 3,4-dimethylphenol
\end{tabular}

Note: Numbers refer to peaks identified in Figure 10.

Table 7. Relative abundances of the indicated compound classes in pyrolysates of MAP turbidites.

\begin{tabular}{|c|c|c|c|c|c|c|c|c|}
\hline $\begin{array}{l}\text { Core, section } \\
\text { interval }(\mathrm{cm})\end{array}$ & $\begin{array}{c}\text { Alkanes/alkenes } \\
(\%)\end{array}$ & $\begin{array}{l}\text { Isoprenoids } \\
(\%)\end{array}$ & $\begin{array}{c}\text { Alkylphenols } \\
(\%)\end{array}$ & $\begin{array}{c}\text { Alkylnaphthalenes } \\
(\%)\end{array}$ & $\begin{array}{c}\text { Alkylbenzenes } \\
(\%)\end{array}$ & $\begin{array}{c}\text { Alkylthiophenes } \\
(\%)\end{array}$ & $\begin{array}{c}\text { Methylketones } \\
(\%)\end{array}$ & $\begin{array}{c}\text { Alkylindenes } \\
(\%)\end{array}$ \\
\hline \multicolumn{9}{|l|}{ 157-951B- } \\
\hline $3 X, 79-84$ & 52 & 4 & 7 & 4 & 19 & 7 & 4 & 3 \\
\hline $3 \mathrm{X}, 93-101$ & 37 & 15 & 8 & 4 & 18 & 12 & 3 & 3 \\
\hline $3 \mathrm{X}, 107-117$ & 39 & 14 & 7 & 4 & 18 & 13 & 3 & 2 \\
\hline \multicolumn{9}{|l|}{$157-952 \mathrm{~A}-$} \\
\hline $9 \mathrm{H}, 50-57$ & 55 & 9 & 4 & 4 & 21 & 3 & 2 & 2 \\
\hline 9H, 94-104 & 36 & 19 & 7 & 4 & 21 & 6 & 3 & 3 \\
\hline $9 \mathrm{H}, 10-20$ & 37 & 20 & 8 & 4 & 19 & 6 & 3 & 3 \\
\hline $18 \mathrm{X}, 101-111$ & 54 & 10 & 7 & 4 & 16 & 4 & 3 & 3 \\
\hline $18 \mathrm{X}, 121-131$ & 39 & 16 & 9 & 4 & 17 & 9 & 3 & 2 \\
\hline $18 X, 55-64$ & 39 & 17 & 7 & 4 & 18 & 9 & 3 & 3 \\
\hline $23 X, 46-52$ & 62 & 6 & 6 & 3 & 15 & 3 & 3 & 3 \\
\hline $23 \mathrm{X}, 74-84$ & 44 & 16 & 6 & 4 & 18 & 8 & 2 & 2 \\
\hline $23 X, 31-41$ & 40 & 16 & 9 & 4 & 18 & 9 & 3 & 3 \\
\hline
\end{tabular}

